\title{
Regiões do entorno dos projetos de extração e transformação mineral na Amazônia Oriental*
}

Maria Célia Nunes Coelho - Professora do Departamento de Geografia da Universidade Federal do Rio de Janeiro (UFRJ).

Maurílio de Abreu Monteiro - Professor do Núcleo de Altos Estudos Amazônicos da Universidade Federal do Pará (UFPA).

Adaise Lopes - Mestre em Planejamento do Desenvolvimento e Doutoranda pela Université de Pau, França.

Sergio Bacury Lira - Professor do Departamento de Economia da Universidade Federal do Pará (UFPA).

\section{Resumo}

Tentativas estratégicas de modernização para a Amazônia Oriental brasileira recorreram com freqüência à indução da concentração espacial de grandes volumes de capitais, e delas resultou o surgimento de grandes plantas mínero-metalúrgicas na região. Face ao que, o artigo analisa as principais mudanças ocorridas nos municípios situados no entorno dos projetos de extração e transformação mineral e indicando que, contrariamente às predições governamentais, há limitada capacidade destas atividades dinamizarem este entorno.

\section{Palavras-chave}

Amazônia,mineração, metalurgia, desenvolvimento regional

\section{Abstract}

The tentative strategies in the modernization of Brazilian Oriental Amazon happened frequently to the induction in the spatial concentration of great amount of capitals and it resulted the appearance of large mineral-metallurgic plants in the region. The article analyses the main changes occurring in the cities around the mineral extraction and transformation operations contrary to the governmental predictions that there was limited capacity for these activities to promote the quality of life in this region.

\section{Keywords}

Amazon, mining, metallurgy, regional development

* A elaboração deste artigo contou com o apoio do CNPq. 


\section{INTRODUÇÃO}

Dois grupos de estratégias de modernização regional marcaram e marcam a história recente da Amazônia. Enquanto um deles consistiu nas tentativas de estabelecimento de pólos de crescimento econômico e de complexos industriais motrizes, o outro diz respeito aos esforços para estimular eixos estruturadores de desenvolvimento regional. Ambos se baseiam em postulados teóricos distintos. No primeiro grupo de estratégias, julga-se ser necessária a participação estatal para contraarrestar dinâmicas produzidas pelo mercado, considerando-se que a modernização de certas regiões não ocorreria sem a ação do Estado. Já o segundo grupo integra estratégias de desenvolvimento regional baseadas no suposto da eficácia das dinâmicas de mercado. Mas em todos os casos trata-se de estratégias de modernização que privilegiam as vantagens comparativas e que, conseqüentemente, tendem a ser espacialmente seletivas e, portanto, concentradoras de mudanças sociais: nos primeiros casos, em torno de um pólo, de um complexo industrial motriz; no último, ao longo de um eixo. Tais estratégias atraem fluxos de capitais e fluxos migratórios intensos e produzem impactos no crescimento urbano e na reestruturação dos municípios amazônicos. No contexto tanto dos pólos de crescimento quanto dos eixos de integração, as infra-estruturas combinadas e as atividades econômicas estimuladas reestruturam áreas geográficas que vão além do espaço a elas restrito. Tal processo, todavia, escapava a análises acadêmicas apoiadas na aplicação do conceito de enclave, recorrente na literatura acadêmica relativa às avaliações dos impactos da implantação de empresas de extração e transformação mineral.

As áreas externas aos municípios-sede de projetos infraestruturais ou nas quais se implantaram empresas de extração e transformação mineral são inevitavelmente afetadas pelas mudanças físicas e socioespaciais por eles suscitadas, por corresponderem ao espaço de destino da migração, da mobilidade e da mobilização das populações por eles atraídas. Insistir então no conceito de enclave significaria continuar sem saber qual é a relevância de tais projetos em termos de mudanças nas formas produtivas preexistentes e nas relações político-sociais e espaciais até então vigentes. Não é, todavia, nosso interesse neste artigo delimitar o alcance espacial da influência exercida por esses projetos, mas reconhecer que eles redirecionam trajetórias históricas dos territórios preexistentes e examinar os elementos geradores de diferenciações e desigualdades sociais e espaciais resultantes das políticas estratégicas regionais de desenvolvimento expressas nos sucessivos planos nacionais, regionais e estaduais. 
Tudo isso torna a presente análise dos resultados econômicofinanceiros e sociais dessas tentativas estratégicas de modernização mais pertinente no sentido de que podemos produzir indicações importantes sobre prováveis desdobramentos da tentativa de modernização vinculada à implantação de eixos de integração previstos pelo "Avança Brasil" (2000-2003).

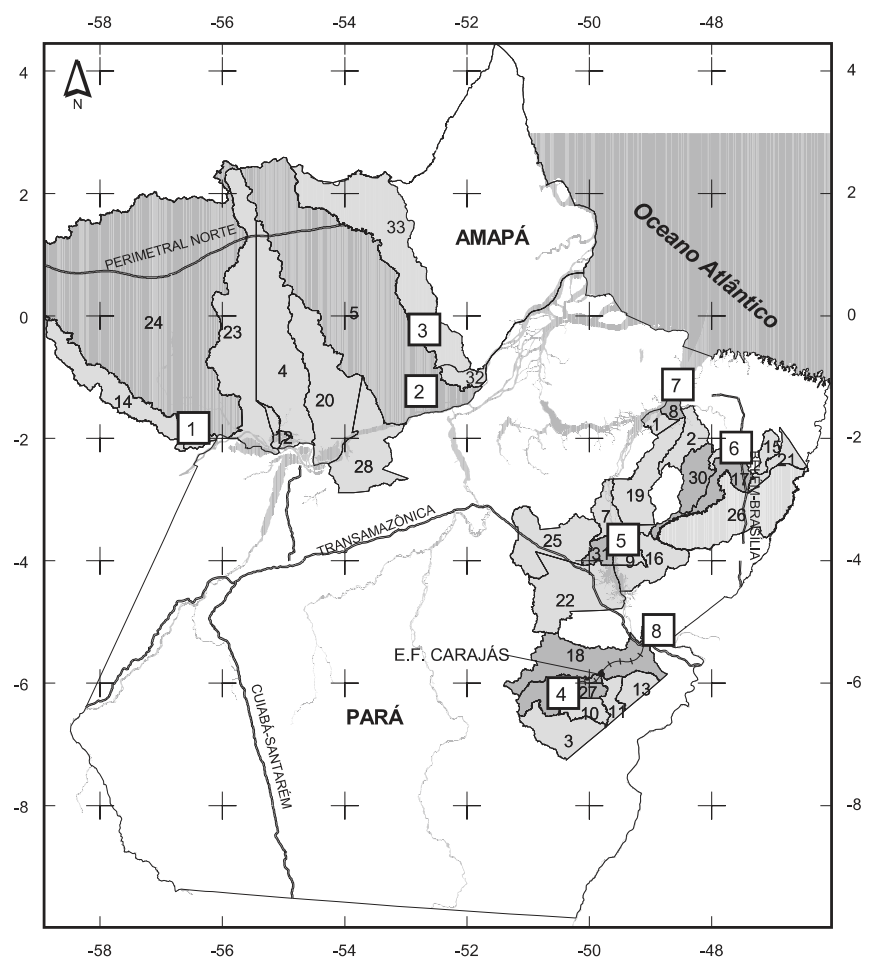

\begin{tabular}{|c|c|}
\hline \multicolumn{2}{|r|}{ Legenda } \\
\hline Muni & cípios \\
\hline 1 & Abaetetuba \\
\hline 2 & Acará \\
\hline 2 & Água azul do Norte \\
\hline 4 & Alenquer \\
\hline 5 & Almeirim \\
\hline 6 & Aurora do Pará \\
\hline 7 & Baião \\
\hline 8 & Barcarena \\
\hline 9 & Breu Branco \\
\hline 10 & Canaã do Carajás \\
\hline 11 & Curionópolis \\
\hline 12 & Curuá \\
\hline 13 & Eldorado dos Carajás \\
\hline 14 & Faro \\
\hline 15 & Garrafão do Norte \\
\hline 16 & Goianésia do Pará \\
\hline 17 & Ipuxuna do Pará \\
\hline 18 & Marabá \\
\hline 19 & Moju \\
\hline 20 & Monte Alegre \\
\hline 21 & Nova Esperança do Piriá \\
\hline 22 & Novo Repartimento \\
\hline 23 & Óbidos \\
\hline 24 & Oriximiná \\
\hline 25 & Pacajá \\
\hline 26 & Paragominas \\
\hline 27 & Parauapebas \\
\hline 28 & Prainha \\
\hline 29 & Terra Santa \\
\hline 30 & Tomé-Açu \\
\hline 31 & Tucurui \\
\hline 32 & Laranjal do Jarí \\
\hline 33 & Vitória do Jarí \\
\hline
\end{tabular}

Figura 1: Municípios e entorno de projetos de extração e transformação de minerais nos estados do Pará e Amapá.

Fonte: Elaborado pelos autores.

\section{EMPRESAS DE EXTRAÇÃO E TRANSFORMAÇÃO MINERAL: MUNICÍPIOS-SEDE E SEU ENTORNO}

A história da divisão interna dos estados em municípios e da distribuição e dinâmica da população nos municípios do Pará mudou com a implantação de infra-estruturas básicas (transporte, telecomunicação e energia) e de projetos industriais a partir da década de 70 do século XX. Todavia, as regiões do entorno da empresa produtora de energia (UHE Tucuruí) e das indústrias de extração e transformação mineral evoluíram de forma distinta. 
As novas indústrias não se estabeleceram em grandes cidades como Belém, Castanhal e Santarém, mas em localidades que, só mais tarde, deram origem a cidades ou em núcleos urbanos de dimensão reduzida por ocasião da implantação dos projetos infra-estruturais e produtivos do período. Por razões de economia de transporte, as unidades de extração e beneficiamento primário do minério foram instaladas próximo das jazidas, obedecendo ao modelo espacial, descrito por Bunker como típico das economias extrativas (BUNKER, 1994, 2001). Isso aconteceu com a Mineração Rio do Norte (MRN), implantada em Porto Trombetas, a aproximadamente $1700 \mathrm{~km}$ de distância da sede municipal de Oriximiná, e com a Companhia Vale do Rio Doce (CVRD), que instalou o beneficiamento primário do ferro na serra dos Carajás, a 694 km de distância da sede do município de Marabá.

Seguindo o padrão comum às economias de produção industrial, os acionistas da Albras decidiram pela implantação das indústrias de transformação nas vizinhanças do porto de Barcarena, localizado próximo a Belém, capital do Estado do Pará, enquanto os acionistas da Alumar optaram pela área portuária de São Luís, capital do Estado do Maranhão. São Luís é o caminho dos navios que seguem rumo aos mercados internacionais. Barcarena tinha a vantagem de estar localizada ao norte da hidrelétrica de Tucuruí, nas margens da baía do Marajó, onde deságua o rio Tocantins. A localização das indústrias nessa cidade facilitou a extensão dos linhões que se dirigem praticamente em linha reta de Tucuruí para esse município. Além do linhão de Tucuruí-Barcarena, outro se dirige para o sul, porém, à altura de Marabá, esse linhão bifurca-se. Uma de suas ramificações segue a direção leste, descrevendo uma trajetória que o conduz a São Luís, com a finalidade de abastecer a Alumar de energia elétrica. 


\begin{tabular}{|c|c|c|c|c|c|c|}
\hline \multirow{2}{*}{$\begin{array}{l}\text { Municípios-sede e } \\
\text { regiões do entorno }\end{array}$} & \multirow{2}{*}{$\begin{array}{l}\text { Ano de } \\
\text { criação }\end{array}$} & \multirow{2}{*}{$\begin{array}{l}\text { Empreendimento(s) principal(ais) e } \\
\text { secundário(s)/Data de operação }\end{array}$} & \multicolumn{4}{|c|}{ Dimensão dos munícipios (em km²) } \\
\hline & & & 1970 & 1990 & 1996 & 2000 \\
\hline Oriximiná & 1894 & Mineração Rio do Norte (1979) & 109.122 & 109.122 & $107.842,39$ & $107.604,0$ \\
\hline Terra Santa & 1991 & & - & - & $1.818,45$ & $1.900,5$ \\
\hline Faro & 1892 & & 15.376 & 15.376 & $1.967,96$ & $11.767,7$ \\
\hline Óbidos & 1854 & & 28.704 & 28.704 & $26.399,99$ & $26.706,0$ \\
\hline Curuá & 1995 & & - & - & $1.685,36$ & $1.473,6$ \\
\hline Alenquer & 1881 & & 22.692 & 22.692 & $24.022,46$ & $24.387,6$ \\
\hline Parauapebas & 1988 & $\begin{array}{c}\text { CVRD-ferro (1984), manganês (1985) } \\
\text { e ouro (1990) }\end{array}$ & - & 17.806 & $6.980,36$ & $7.046,7$ \\
\hline Curionópolis & 1988 & & - & 5.247 & $2.261,10$ & $2.269,2$ \\
\hline Canaã dos Carajás & 1994 & & - & - & $3.053,85$ & $3.147,9$ \\
\hline Água Azul do Norte & 1991 & & - & - & $7.619,55$ & $7.626,0$ \\
\hline Marabá & 1913 & $\begin{array}{l}\text { COSIPA (1989), SIMARA (1989), USI- } \\
\text { MAR (2002), Siderúrgica Terra Norte } \\
\text { (2002) e Siderúrgica Ibérica (2002) }\end{array}$ & 37.373 & 14.320 & $15.288,126$ & $15.092,3$ \\
\hline Eldorado de Carajás & 1991 & & - & - & $2.931,11$ & $2.956,7$ \\
\hline Barcarena & 1943 & $\begin{array}{c}\text { ALBRÁS (1985), ALUNORTE (1995), } \\
\text { Imerys Capim Caulim (1996), PPSA } \\
\text { (1996) e SOINCO (1997) }\end{array}$ & 895 & 895 & $1.300,02$ & $1.310,3$ \\
\hline Abaetetuba & 1895 & & 1.090 & 1.090 & $1.521,45$ & $1.606,8$ \\
\hline Moju & 1896 & & 11.728 & 11.728 & $8.865,00$ & $9.681,2$ \\
\hline Acará & 1875 & & 8.542 & 4.093 & $4.289,58$ & $4.344,2$ \\
\hline Almeirim & 1890 & $\begin{array}{l}\text { CADAM (1977), JARI Florestal (1979) } \\
\text { e Mineração Santa Lucrécia (1981) }\end{array}$ & 67.870 & 67.870 & $72.347,13$ & $72.961,4$ \\
\hline Prainha & 1869 & & 32.642 & 10.422 & $13.920,49$ & $13.834,0$ \\
\hline Monte Alegre & 1880 & & 26.762 & 26.762 & $19.606,47$ & $19.977,0$ \\
\hline Laranjal do Jari (AP) & 1987 & JARI Florestal (1979) & - & 33.422 & $31.170,00$ & $31.170,0$ \\
\hline Vitória do Jari (AP) & 1994 & CADAM (1977) & - & - & $2.428,00$ & $2.482,5$ \\
\hline Tucuruí & 1947 & Hidrelétrica de Tucuruí (1984) & 5.124 & 5.124 & $1.953,98$ & $2.086,2$ \\
\hline Breu Branco & 1991 & Camargo Corrêa e Metais S.A. (1988) & - & - & $4.013,46$ & $3.971,4$ \\
\hline Novo Repartimento & 1991 & & - & - & $14.565,84$ & $15.396,4$ \\
\hline Pacajá & 1998 & & - & - & $16.801,49$ & $11.832,1$ \\
\hline Baião & 1883 & & 4.428 & - & $4.428,00$ & $3.188,2$ \\
\hline Goianésia do Pará & 1991 & & - & - & $7.174,40$ & $6.928,2$ \\
\hline
\end{tabular}

Quadro 1: Situação dos municípios nas regiões do entorno de grandes projetos infra-estruturais e industriais nos estados do Pará e Amapá.

Fonte: IBGE e dados de pesquisa. 


\section{CRESCIMENTO POPULACIONAL E SURGIMENTO DE NOVOS MUNICÍPIOS}

A trajetória populacional foi analisada com base em três períodos da história recente da industrialização da Amazônia Oriental, correspondentes às três últimas décadas do século XX. No primeiro período, de 1970 a 1980, os municípios-sede dos projetos produtivos e infra-estruturais de grande porte apresentaram taxas geométricas de crescimento populacional elevadas. Foi o caso de Tucuruí (19,94\%), Almeirim (10,78\%), Marabá (9,37\%) e Oriximiná (4,73\%) (Quadro 2). Em menor grau, a expansão da frente madeireira no Leste do Pará explicava a taxa relativamente elevada (4,73\%) de Moju, pertencente ao agrupamento de municípios liderados por Barcarena, cuja industrialização se deu no segundo período a ser ainda analisado.

Nesse período, tanto os municípios-sede das empresas quanto os seus vizinhos receberam grande contingente de migrantes de diferentes origens. A população aumentou muito mais do que as administrações locais podiam suportar. A ocupação cresceu particularmente em alguns municípios vizinhos dos empreendimentos, como foi o caso de Prainha, vizinho de Almeirim, que alcançou uma taxa de crescimento de 13,94\%. Novos núcleos surgiram além daqueles criados pelas empresas. Na região do antigo município de Marabá, o processo migratório contribuiu decisivamente para aumentar o número de povoados que se colocavam como embriões de formação de novos municípios.

No segundo período, de 1980 a 1991, Barcarena, com uma taxa de 7,84\%, foi o município que mais cresceu. Nesse município as obras de instalação da Albras e da Alunorte iniciaram em 1980. Enquanto a Albras começou a operar em 1985, a Alunorte teve sua construção interrompida nesse período. Os demais municípios-sede de grandes projetos produtivos e infra-estruturais, implantados no período anterior a esse, continuaram a crescer, porém em ritmo menos acelerado. Marabá cresceu a uma taxa de 6,81\%, Oriximiná, 3,04\% e Tucuruí, 2,66\%. Este último sofria as conseqüências da conclusão das obras de construção da hidrelétrica de Tucuruí, inaugurada em 1984. A exceção ficou por conta de Almeirim, que praticamente não cresceu, apresentando uma taxa de apenas $0,10 \%$. Prainha, seu vizinho, teve crescimento negativo $(-4,68 \%)$. Devido à falta de empregos locais, esses municípios perdiam população, que migrava para outras partes do Estado. É preciso dizer que as indústrias localizadas em Almeirim foram responsáveis pelo crescimento e pela geração de novos municípios (Laranjal do Jari e Vitória do Jari) muito mais no Estado vizinho do Amapá do que no lado paraense. 
A queda do crescimento de Marabá - de 9,37\% no primeiro período para 6,81\% no segundo - pode ser também atribuída à fragmentação de seu território devido à criação de dois novos municípios, que tiveram origem no crescimento de dois núcleos urbanos. Localizado ao lado do portão colocado pela CVRD, no encontro do rio Parauapebas com a rodovia PA275, que conecta a serra do Carajás à rodovia PA-150 e, conseqüentemente, à cidade de Marabá, o núcleo urbano de Parauapebas tinha sido inicialmente criado como apoio às atividades da mineração e do transporte do ferro. A população atraída pela possibilidade de empregos na CVRD e nas empresas prestadoras de serviços a essa companhia tornou seu crescimento populacional incontrolável. Em 1988, o município de Parauapebas foi desmembrado de Marabá. Nesse mesmo ano, destino similar foi reservado ao antigo núcleo, conhecido como Quilômetro Trinta, situado à margem da rodovia PA-275, de apoio às atividades de garimpo de Serra Pelada. O Quilômetro Trinta deu origem à cidade e ao município de Curionópolis.

\begin{tabular}{|l|c|c|c|c|c|c|c|}
\hline \multirow{2}{*}{ Municípios } & \multicolumn{4}{|c|}{ População } & \multicolumn{3}{c|}{ Taxas de crescimento anual (\%) } \\
\cline { 2 - 9 } & 1970 & 1980 & 1991 & \multicolumn{1}{c|}{2000} & $1970 / 1980$ & $1980 / 1991$ & $1991 / 2000$ \\
\hline Barcarena & 17.498 & 20.021 & 45.946 & 63.259 & 1,36 & 7,84 & 3,62 \\
\hline Abaetetuba & 57.520 & 74.545 & 99.989 & 119.072 & 2,63 & 2,71 & 1,97 \\
\hline Moju & 18.035 & 28.628 & 44.424 & 52.941 & 4,73 & 4,08 & 1,97 \\
\hline Acará & 24.487 & 35.269 & 37.184 & 52.126 & 3,72 & 0,48 & 3,82 \\
\hline Oriximiná & 18.994 & 29.594 & 41.154 & 48.332 & 4,53 & 3,04 & 1,80 \\
\hline Terra Santa & - & - & - & 14.592 & - & - & - \\
\hline Faro & 10.054 & 12.595 & 13.574 & 10.037 & 2,28 & 0,68 & $-3,30$ \\
\hline Óbidos & 26.226 & 38.002 & 42.307 & 46.490 & 3,70 & 0,96 & 1,05 \\
\hline Curuá & - & - & - & 9.224 & - & - & - \\
\hline Alenquer & 35.021 & 44.539 & 52.856 & 41.784 & 2,43 & 1,57 & $-2,58$ \\
\hline Parauapebas & - & - & 53.335 & 71.568 & - & - & 3,32 \\
\hline Curionópolis & - & - & 38.672 & 19.486 & - & - & $-7,33$ \\
\hline Canaã dos Carajás & - & - & - & 10.922 & - & - & - \\
\hline Água Azul do Norte & - & - & - & 22.084 & - & - & - \\
\hline Marabá & 24.474 & 59.915 & 123.668 & 16.020 & 9,37 & 6,81 & 3,46 \\
\hline Eldorado de Carajás & - & - & & 29.608 & - & - & - \\
\hline Almeirim & 11.889 & 33.082 & 33.442 & 33.957 & 10,78 & 0,10 & 0,17 \\
\hline Prainha & 12.304 & 45.358 & 26.782 & 27.301 & 13,94 & $-4,68$ & 0,21 \\
\hline Laranjal do Jari (AP) & - & - & 21.372 & 28.196 & - & - & 4,70 \\
\hline Vitória do Jari (AP) & - & - & - & 8.550 & - & - & 7,36 \\
\hline Tucuruí & 9.921 & 61.140 & 81.623 & 73.798 & 19,94 & 2,66 & $-1,11$ \\
\hline Breu Branco & - & - & - & 32.446 & - & - & - \\
\hline Novo Repartimento & - & - & - & 41.817 & - & - & - \\
\hline Pacajá & - & - & 30.777 & 28.888 & - & - & $-0,70$ \\
\hline Baião & 12.134 & 16.261 & 20.072 & 21.119 & 2,97 & 1,93 & 0,57 \\
\hline Goianésia do Pará & - & - & - & 22.685 & - & - & - \\
\hline
\end{tabular}

Quadro 2: Crescimento da população municipal.

Fonte: Dados do IBGE, referentes aos anos de 1970, 1980, 1991 e 2000. 
No terceiro período, de 1991 a 2000, o ritmo de crescimento da população dos municípios-sede dos grandes projetos havia caído ainda mais. Todavia, Barcarena, Marabá e Parauapebas apresentaram ainda taxas consideradas elevadas, 3,62\%, 3,46\% e 3,32\% respectivamente. A população de Almeirim praticamente se manteve no mesmo patamar do período anterior. Tucuruí chegou inclusive a apresentar uma taxa de crescimento negativo de $-1,11 \%$.

$\mathrm{Na}$ área correspondente ao município de Marabá, nas décadas anteriores a 1980, novas condições demográficas ajudaram no processo de fragmentação territorial desse município e dos municípios então gerados. Nesse período, uma segunda e uma terceira geração de municípios surgiram indiretamente do antigo município de Marabá. Em 1991, Parauapebas (criado em 1988) deu origem ao município de Água Azul do Norte, em uma área da colonização do Grupo Executivo de Terras do Araguaia e Tocantins (Getat) - datada de 1981-1982 - mais afastada do núcleo urbano de Parauapebas, correspondente ao Cedere III. Naquele mesmo ano, Curionópolis deu origem ao município de Eldorado dos Carajás, cujo núcleo serviu de apoio a madeireiras, ao garimpo de Serra Pelada e a assentamentos do Getat. Numa terceira geração, em 1994, foi desmembrado de Parauapebas o município de Canaã dos Carajás, tendo como sede o núcleo Cedere II, criado pelo Getat nas proximidades do então núcleo urbano de Parauapebas.

O fato mais interessante desse período foi o decréscimo da população nos novos municípios que surgiram como apoio à atividade de garimpo de Serra Pelada. Foi o caso de Curionópolis, que perdeu população com o fechamento das minas, atingindo uma taxa de $-7,33 \%$. Além de Curionópolis, alguns municípios vizinhos dos municípios-sede dos grandes projetos produtivos e infra-estruturais apresentaram taxas negativas elevadas, como Faro, com $-3,30 \%$, Alenquer, $-2,58 \%$, os municípios situados na área de influência de Oriximiná e de Pacajá, -0,70\%.

Dos cinco grupamentos de municípios, aqueles situados em volta de Tucuruí e Marabá-Parauapebas foram os que sofreram maiores mudanças, correspondentes às diferentes etapas de fragmentação dos antigos territórios municipais de Marabá e Tucuruí. Isso se deveu ao fato de que, para Marabá e Tucuruí, convergiram grandes contingentes migratórios atraídos pela abertura da estrada e da ferrovia, pelos projetos de colonização, mas, sobretudo, pela construção da hidrelétrica de Tucuruí e pela exploração do ferro e ouro na região de Carajás. O agrupamento em torno de Barcarena correspondeu às áreas de malha de divisão territorial municipal menos alterada, por se tratar de municípios de ocupação muito antiga e já consolidada. 


\section{TENDÊNCIAS À URBANIZAÇÃO}

A tendência de urbanização da Amazônia tem sido objeto de análise de diferentes autores (BECKER, 1982; BECKER; EGLER, 1992; MACHADO, 1999; SAWYER, 1980, 2001; HURTIENNE, 2001), que discordam entre si quanto à magnitude, à generalização e ao significado do fenômeno. Alguns autores, como Hurtienne (2001), chamam a atenção para a desigualdade desse fenômeno na Amazônia. No período de 1970 a 1980 (Quadros 3 e 4), assim como o crescimento urbano, o rural também foi positivo. Tucuruí foi o município de maior taxa de crescimento urbano. Na sede desse município, crescia a população em busca de oportunidade de emprego na construção da hidrelétrica ali implantada. Em Tucuruí e em Marabá, crescia também a população que se dirigia para sua área rural atraída pelos projetos de colonização ou pelas terras de acesso facilitado pela abertura da rodovia Transamazônica. O município de Barcarena foi o único a perder população rural em função de sua estagnação agrícola e por estar, nesse momento, distante dos projetos estimulados pelo governo federal. As unidades municipais vizinhas aos municípios-sede de empresas também apresentavam taxas de crescimento urbano e rural relativamente altas, o que comprova o fato de que o processo de migração desencadeado pelos projetos produtivos e infra-estruturais considerados não produz efeito pontual, podendo atingir municípios vizinhos ou mesmo áreas situadas a maiores distâncias, fato não captado pelo procedimento adotado nesta pesquisa.

Nos períodos de 1980 a 1991 e de 1990 a 2000 (Quadros 3 e 4), as taxas de crescimento urbano permaneceram elevadas para a maioria dos municípios então sedes dos projetos produtivos e infra-estruturais e seus vizinhos. Ao contrário do período anterior, Barcarena destacava-se pelas taxas positivas de crescimento (urbano e rural) elevadas nos dois períodos. O crescimento da população rural deve-se ao fato de que a chegada de migrantes nordestinos foi maior que a saída da população total no conjunto do município. Nesse município, a migração do campo para a cidade ficou quase restrita às comunidades diretamente afetadas pelas grandes empresas do alumínio que lá se instalaram na década de 80 e do caulim, na década de 90.

Nesses dois períodos considerados, as taxas relativamente elevadas de crescimento urbano de Marabá e Parauapebas estavam, sobretudo, vinculadas ao fato de que a partir de 1989, com a redução nas atividades de garimpo de Serra Pelada, havia aumentado a população dos desempregados nas periferias das cidades e dos núcleos urbanos existentes. Aumentava também nesses municípios a pressão sobre a terra, monopolizada pelos grandes senhores de terra. 
Tomando como referência o ano de 1991, os municípios-sede dos projetos infra-estruturais e industriais tiveram suas populações urbanas distribuídas entre os distritos concernentes à sede municipal e às localidades criadas pelas empresas (vilas ou cidades-empresas) ou suas periferias conhecidas como beiradões (Quadro 5). Apenas para o município de Oriximiná, no qual a MRN já tinha alcançado uma fase estável de funcionamento, foi constatado um número reduzido de população, inferior a 1000 habitantes, vivendo nas vilas das empresas e no beiradão.

\begin{tabular}{|c|c|c|c|c|c|c|c|}
\hline \multirow{2}{*}{ Municípios } & \multirow{2}{*}{$\begin{array}{c}\text { Pop. } \\
\text { urbana } \\
\text { em } 1970\end{array}$} & \multirow{2}{*}{$\begin{array}{c}\text { Pop. } \\
\text { urbana } \\
\text { em } 1980\end{array}$} & \multirow{2}{*}{$\begin{array}{c}\text { Pop. } \\
\text { urbana } \\
\text { em } 1991\end{array}$} & \multirow{2}{*}{$\begin{array}{c}\text { Pop. } \\
\text { urbana } \\
\text { em } 2000\end{array}$} & \multicolumn{3}{|c|}{ Taxas de crescimento anual (\%) } \\
\hline & & & & & $1970 / 1980$ & $1980 / 1991$ & $1991 / 2000$ \\
\hline Barcarena & 2.388 & 6.700 & 21.629 & 27.772 & 10,87 & 11,24 & - \\
\hline Abaetetuba & 19.661 & 33.831 & 56.389 & 70.752 & 5,58 & 4,75 & 2,57 \\
\hline Moju & 920 & 3.544 & 9.748 & 17.626 & 14,44 & 9,63 & 6,8 \\
\hline Acará & 1.339 & 3.401 & 5.719 & 9.745 & 9,77 & 4,84 & 6,1 \\
\hline Oriximiná & 6.771 & 12.029 & 21.163 & 28.181 & 5,92 & 5,27 & 3,23 \\
\hline Terra Santa & - & - & - & 10.965 & - & - & - \\
\hline Faro & 4.361 & 6.599 & 8.884 & 4.918 & 4,23 & 2,74 & $-6,36$ \\
\hline Óbidos & 8.925 & 17.711 & 20.147 & 22.978 & 7,09 & 1,18 & 1,47 \\
\hline Curuá & - & - & - & 2.933 & - & - & - \\
\hline Alenquer & 11.687 & 17.755 & 21.958 & 25.160 & 4,27 & 1,95 & 1,52 \\
\hline Parauapebas & - & - & 27.443 & 59.260 & - & - & 8,93 \\
\hline Curionópolis & - & - & 15.074 & 13.250 & - & - & $-1,42$ \\
\hline Canaã dos Carajás & - & - & - & 3.924 & - & - & - \\
\hline Água Azul do Norte & - & - & - & 2.827 & - & - & - \\
\hline Marabá & 14.585 & 41.657 & 102.435 & 134.373 & 11,07 & 8,52 & 3,06 \\
\hline Eldorado dos Carajás & - & - & - & 14.112 & - & - & - \\
\hline Almeirim & 3.563 & 4.851 & 16.342 & 18.916 & 3,13 & 11,67 & 1,64 \\
\hline Prainha & 1.728 & 3.332 & 4.196 & 7.149 & 6,79 & 2,12 & 6,1 \\
\hline Laranjal do Jari & - & - & 14.301 & 26.487 & - & - & - \\
\hline Vitória do Jari & - & - & - & 6.887 & - & - & 4,2 \\
\hline Tucuruí & 5.677 & 27.261 & 46.014 & 60.918 & 16,99 & 4,87 & 3,17 \\
\hline Breu Branco & - & - & - & 15.952 & - & - & - \\
\hline Novo Repartimento & - & - & - & 15.524 & - & - & - \\
\hline Pacajá & - & - & 4.160 & 7.604 & - & - & 6,93 \\
\hline Baião & 2.763 & 4.110 & 7.877 & 10.865 & 4,05 & 6,09 & 3,64 \\
\hline Goianésia do Pará & - & - & - & 14.878 & - & - & - \\
\hline
\end{tabular}

Quadro 3: Crescimento da população urbana.

Fonte: Dados do IBGE, referentes aos anos de 1970, 1980, 1991 e 2000.

O monopólio dificultou o acesso à terra para um grande contingente de migrantes. Além do mais, o desenvolvimento das atividades de extração e transformação mineral não tinha conquistado grandes mercados para os produtos agrícolas e pecuários regionais. Conseqüentemente, alguns municípios situados no entorno dos municípios-sede dos projetos infraestruturais e produtivos apresentaram taxas negativas de crescimento rural. No município madeireiro de Paragominas, na Belém-Brasília, por exemplo, a taxa de crescimento rural continuou a decrescer em função do pouco estímulo à produção familiar. 
Na década de 70, a dinâmica regional reestruturava-se a partir das cidades então revitalizadas ou emergentes ao longo das vias de circulação. A política de polarização (Polamazônia) atribuía um papel dinamizador à cidade. Num primeiro momento, Marabá, Tucuruí e Abaetetuba, cidades de origem ribeirinha, tiveram reforçados seus papéis tradicionais como centros estruturadores do espaço (Quadro 6). Nesse momento (de 1960 a 1980), a cidade de Tucuruí era a que apresentava a maior taxa de crescimento, em virtude das obras de construção da usina hidrelétrica. Num segundo momento (da década de 80 à década de 90), as cidades de Marabá (sob a influência da CVRD) e Paragominas (com seu pólo madeireiro) cresceram de forma espetacular. Num terceiro momento, particularmente as cidades de

\begin{tabular}{|c|c|c|c|c|c|c|c|}
\hline \multirow{2}{*}{ Municípios } & \multirow{2}{*}{$\begin{array}{c}\text { Pop. } \\
\text { rural em } \\
1970\end{array}$} & \multirow{2}{*}{$\begin{array}{c}\text { Pop. } \\
\text { rural em } \\
1980\end{array}$} & \multirow{2}{*}{$\begin{array}{l}\text { Pop. } \\
\text { rural em } \\
1991\end{array}$} & \multirow{2}{*}{$\begin{array}{l}\text { Pop. } \\
\text { rural em } \\
2000\end{array}$} & \multicolumn{3}{|c|}{ Taxas de crescimento anual (\%) } \\
\hline & & & & & $1970 / 1980$ & $1980 / 1991$ & $1991 / 2000$ \\
\hline Barcarena & 15.110 & 13.321 & 24.317 & 35.487 & $-1,25$ & 5,62 & 4,29 \\
\hline Abaetetuba & 37.859 & 40.714 & 43.600 & 48.320 & 0,73 & 0,62 & 1,25 \\
\hline Moju & 17.115 & 25.084 & 34.676 & 35.315 & 3,9 & 2,99 & 0,2 \\
\hline Acará & 23.148 & 31.868 & 31.465 & 42.381 & 3,25 & $-0,12$ & 3,36 \\
\hline Oriximiná & 12.223 & 17.565 & 19.991 & 19.151 & 3,69 & 1,18 & $-0,48$ \\
\hline Terra Santa & - & - & - & 3.627 & - & - & - \\
\hline Faro & 5.693 & 5.996 & 4.690 & 5.119 & 0,52 & $-2,21$ & 0,98 \\
\hline Óbidos & 17.501 & 20.291 & 22.160 & 23.512 & 1,49 & 1,18 & 1,47 \\
\hline Curuá & - & - & - & 6.291 & - & - & - \\
\hline Alenquer & 23.334 & 26.784 & 30.898 & 16.624 & 1,38 & 1,31 & $-6,66$ \\
\hline Parauapebas & - & - & 25.892 & 12.308 & - & - & $-7,93$ \\
\hline Curionópolis & - & - & 23.598 & 6.236 & - & - & $-13,75$ \\
\hline Canaã dos Carajás & - & - & - & 6.998 & - & - & - \\
\hline Água Azul do Norte & - & - & - & 19.257 & - & - & - \\
\hline Marabá & 9.889 & 18.258 & 21.233 & 33.647 & 6,32 & 1,38 & 5,25 \\
\hline Eldorado dos Carajás & - & - & - & 15.496 & - & - & - \\
\hline Almeirim & 8.326 & 28.231 & 17.100 & 15.041 & 12,99 & $-4,46$ & $-1,42$ \\
\hline Prainha & 10.576 & 42.026 & 22.586 & 20.152 & 14,79 & $-5,49$ & $-1,26$ \\
\hline Laranjal do Jari & - & - & 7.071 & 1.709 & - & - & 1,02 \\
\hline Vitória do Jari & - & - & - & 1.663 & - & - & - \\
\hline Tucuruí & 4.244 & 33.879 & 35.609 & 12.880 & 23,09 & 0,45 & $-10,68$ \\
\hline Breu Branco & - & - & - & 16.494 & - & - & - \\
\hline Novo Repartimento & - & - & - & 26.293 & - & - & - \\
\hline Pacajá & - & - & 26.617 & 21.284 & - & - & $-2,45$ \\
\hline Baião & 9.371 & 12.151 & 12.195 & 10.254 & 2,63 & 0,03 & $-1,91$ \\
\hline Goianésia do Pará & - & - & 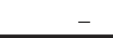 & 7.807 & - & - & - \\
\hline
\end{tabular}

Quadro 4: População rural.

Fonte: Dados do IBGE, referentes aos anos de 1970, 1980, 1991 e 2000. 


\begin{tabular}{|c|c|c|}
\hline Município & $\begin{array}{c}\text { Distrito que contém a sede municipal e localidades } \\
\text { criadas pelas empresas }\end{array}$ & População \\
\hline \multirow{3}{*}{ Almeirim } & Pop. urb. do distrito de Almeirim & 9.065 \\
\hline & Pop. urb. do distrito de Monte Dourado & 7.107 \\
\hline & Cidade industrial Monguba & 1.790 \\
\hline \multirow{4}{*}{ Barcarena } & Pop. urb. do distrito de Barcarena & 18.565 \\
\hline & Vila dos Cabanos (núcleo urbano da Albras) & 6.174 \\
\hline & Vila do Conde (pop. urb. do distrito de Murucupi) & 3.007 \\
\hline & Povoado de Laranjal & 1.308 \\
\hline \multirow{6}{*}{ Oriximiná } & Pop. urb. do distrito de Oriximiná & 21.131 \\
\hline & Acampamento da ENGE-RIO & 9 \\
\hline & Acampamento núcleo mina & 111 \\
\hline & Cachoeira Porteira (beiradão) & 545 \\
\hline & Cachoeira Porteira (Vila Andrade Gutierrez) & 70 \\
\hline & Porto Trombetas & 4.486 \\
\hline \multirow{3}{*}{ Parauapebas } & Pop. urb. do distrito de Parauapebas & 27.452 \\
\hline & Núcleo urbano de Carajás & 5.068 \\
\hline & Núcleo urbano Serra Norte & 1.119 \\
\hline \multirow{2}{*}{ Tucuruí } & Pop. urb. do distrito de Tucuruí & 46.011 \\
\hline & Vila permanente & 6.181 \\
\hline
\end{tabular}

Quadro 5: Distribuição da população dos municípios-sede de projetos em 1991.

Fonte: Censo do IBGE, 1991.

\begin{tabular}{|l|r|r|r|r|r|r|r|r|r|r|}
\hline \multirow{2}{*}{ Cidade } & \multirow{2}{*}{1960} & \multirow{2}{*}{1970} & \multirow{2}{*}{1980} & \multirow{2}{*}{1991} & \multirow{2}{*}{2000} & \multicolumn{5}{|c|}{ Taxa anual de crescimento } \\
\cline { 8 - 12 } & & & & & & $\begin{array}{c}1960 / \\
1970\end{array}$ & $\begin{array}{c}1970 / \\
1980\end{array}$ & $\begin{array}{c}1980 / \\
1991\end{array}$ & $\begin{array}{c}1991 / \\
1996\end{array}$ & $\begin{array}{c}1996 / \\
2000\end{array}$ \\
\hline Abaetetuba & 11.703 & & 33.831 & 56.389 & 69.227 & 5,5 & 5.4 & 4,8 & 2,5 & 2,7 \\
\hline Parauapebas & - & - & - & 27.443 & 59.239 & - & - & - & 10,7 & 3 \\
\hline Marabá & 8.963 & & 41.657 & & & 4,9 & 11,2 & 8,5 & 3,8 & 2,8 \\
\hline Paragominas & - & 1.790 & 12.316 & 40.054 & 58.081 & - & 21,3 & 11,3 & 3,6 & 3,6 \\
\hline Tucuruí & 3.558 & & 27.261 & 46.041 & 60.867 & 1 & 10,4 & 4,9 & 0,8 & 5,8 \\
\hline
\end{tabular}

Quadro 6: Cidades paraenses selecionadas com população > 40.000 habitantes em 2000.

Fonte: Dados do IBGE, referentes aos censos de 1970, 1980, 1991, 1996 e 2000.

Marabá e Tucuruí tiveram seus papéis redefinidos pela emergência de uma nova cidade, Parauapebas, que surgiu no sopé da serra dos Carajás. Contemporaneamente, as cidades de Marabá e Parauapebas constituem-se pólos regionais e sub-regionais cujas funções urbanas extrapolam o âmbito local. A compreensão da dinâmica espacial, sobretudo no Estado do Pará, dada a estruturação das cidades promovida pela implantação, em seus espaços, de empreendimentos de extração e de transformação da matéria-prima, pode ser inferida a partir do contingente de migrantes que recebe. 


\section{REESTRUTURAÇÃO ECONÔMICO-FINANCEIRA, CAPACIDADE DE ARRECADAÇÃO, AUTONOMIA FINANCEIRA E MUDANÇAS SOCIAIS NOS MUNICÍPIOS DAS REGIÕES DE ENTORNO}

A intenção principal deste item é examinar como o processo de implantação de sucessivas políticas públicas de atração de investidores para a Amazônia oriental afetou a evolução econômica dos municípios, alterando suas receitas provenientes das arrecadações tributárias. A capacidade de arrecadação e a busca da autonomia financeira dos municípios estudados variam de forma a expressar, de uma maneira ou de outra, a distribuição espacial dos projetos e as desigualdades sociais então agravadas.

Neste ponto do trabalho, o período de análise ficou restrito ao curto espaço de tempo de 1995 a 2000, o que se deve à dificuldade de tornar comparativos os dados de uma série temporal mais longa, afetada pelas instabilidades monetárias brasileiras. A análise centrada na segunda metade da década de 90 torna-se interessante porque corresponde não só ao período pós-implantação dos projetos mínero-metalúrgicos e pósConstituição de 1988, mas também à fase pós-crise do velho padrão de desenvolvimento construído no pós-guerra e ao auge da desestruturação liberal iniciada nessa década.

\section{IMPACTOS DO CRESCIMENTO POPULACIONAL NA TRANSFERÊNCIA DE IMPOSTOS PARA OS MUNICÍPIOS}

Conforme frisado anteriormente, a implantação de um projeto econômico de grande porte - seja infra-estrutural, seja produtivo - que demanda elevados investimentos de capital e gera expectativas e/ou cria possibilidades de inúmeros empregos localmente, atrai, logo de início, para a região na qual se estabelecerá a empresa, um contingente populacional expressivo, principalmente na fase de construção civil do projeto, ocasionando uma taxa de crescimento elevada que perdura por alguns anos. Independentemente do impacto e dos problemas que se processam no campo social, o importante é que a população constitui um indicador determinante para a redistribuição de alguns dos principais impostos vigentes no país. Por conseguinte, os municípios que absorvem essa população passam a auferir uma maior receita tributária, o mesmo não ocorrendo com os demais no contexto do seu espaço sub-regional ou estadual.

O melhor exemplo dessa situação é o Fundo de Participação dos Municípios (FPM), em que o coeficiente de participação do município é 
determinado exclusivamente pelo número de seus habitantes. Quando o coeficiente de um município aumenta, o valor da sua cota financeira também aumenta, fazendo com que automaticamente a cota individual de todos os outros municípios do mesmo Estado diminua. Isso também ocorre quando é criado um novo município, pois há a redistribuição dos índices de participação dos demais já existentes.

De acordo com o Quadro 7, verifica-se que, no período de 1995 a 2000, a receita do FPM dos municípios-sede teve um crescimento significativo. No caso de Parauapebas, cujo crescimento populacional se manteve alto no período, o valor da receita foi duplicado. Situação semelhante ocorreu nos municípios de Água Azul do Norte, Eldorado dos Carajás, Breu Branco e Goianésia do Pará, que continuam sofrendo intensos fluxos migratórios, devido ao esvaziamento de Serra Pelada, à expansão do setor madeireiro e à ampliação da produção agrícola familiar.

\begin{tabular}{|l|r|r|r|r|r|r|}
\hline \multicolumn{1}{|c|}{ Municípios } & \multicolumn{1}{c|}{19955} & \multicolumn{1}{c|}{1996} & \multicolumn{1}{c|}{1997} & \multicolumn{1}{c|}{1998} & \multicolumn{1}{c|}{1999} & \multicolumn{1}{c|}{2000} \\
\hline \hline Oriximiná & 2.311 .973 & 2.615 .623 & 2.609 .913 & 2.703 .238 & 2.941 .446 & 3.142 .118 \\
\hline Terra Santa & 924.789 & 1.046 .248 & 1.043 .965 & 1.081 .295 & 1.563 .500 & 1.764 .095 \\
\hline Faro & 1.387 .184 & 1.569 .375 & 1.565 .948 & 1.621 .943 & 1.620 .797 & 1.571 .059 \\
\hline Óbidos & 2.543 .170 & 2.877 .188 & 2.870 .905 & 2.973 .562 & 3.241 .593 & 3.469 .422 \\
\hline Curuá & - & - & 782.974 & 810.972 & 938.100 & 1.058 .457 \\
\hline Alenquer & 2.774 .368 & 3.138 .748 & 3.131 .896 & 3.243 .885 & 3.421 .682 & 3.534 .883 \\
\hline Parauapebas & 2.311 .973 & 2.615 .623 & 2.609 .913 & 3.243 .885 & 4.065 .100 & 4.586 .647 \\
\hline Curionópolis & 2.543 .170 & 2.877 .188 & 2.870 .905 & 2.973 .562 & 3.001 .475 & 2.945 .736 \\
\hline Canaã dos Carajás & - & - & 782.974 & 1.081 .295 & 1.250 .800 & 1.411 .276 \\
\hline Água Azul do Norte & 693.592 & 784.687 & 782.974 & 1.621 .943 & 2.188 .900 & 2.469 .733 \\
\hline Marabá & 8.640 .024 & 9.774 .792 & 9.999 .495 & 10.220 .167 & 11.185 .449 & 13.834 .652 \\
\hline Eldorado de Carajás & 924.789 & 1.046 .248 & 1.043 .965 & 1.621 .943 & 1.876 .200 & 2.116 .914 \\
\hline Barcarena & 2.311 .973 & 2.615 .623 & 2.609 .913 & 2.973 .562 & 3.439 .700 & 3.881 .009 \\
\hline Abaetetuba & 3.467 .960 & 3.923 .435 & 3.914 .870 & 4.325 .181 & 5.003 .200 & 5.645 .104 \\
\hline Moju & 2.311 .973 & 2.615 .623 & 2.609 .913 & 2.703 .238 & 3.127 .000 & 3.528 .190 \\
\hline Acará & 3.005 .565 & 3.400 .312 & 3.392 .887 & 3.514 .209 & 3.781 .859 & 3.993 .108 \\
\hline Almeirim & 2.543 .170 & 2.877 .188 & 2.870 .905 & 2.973 .562 & 3.121 .535 & 3.338 .501 \\
\hline Prainha & 1.849 .578 & 2.092 .500 & 2.087 .931 & 2.162 .590 & 2.281 .121 & 2.356 .589 \\
\hline Tucuruí & 3.699 .157 & 4.185 .000 & 4.175 .861 & 4.325 .181 & 4.502 .213 & 4.582 .255 \\
\hline Breu Branco & 1.155 .987 & 1.307 .812 & 1.304 .957 & 1.621 .943 & 1.876 .200 & 2.469 .733 \\
\hline Novo Repartimento & 1.618 .381 & 1.830 .938 & 1.826 .939 & 2.162 .590 & 2.501 .600 & 2.822 .552 \\
\hline Pacajáa & 1.849 .578 & 2.092 .500 & 2.087 .931 & 2.162 .590 & 2.281 .121 & 2.356 .589 \\
\hline Baião & 1.387 .184 & 1.569 .375 & 1.565 .948 & 1.621 .943 & 1.876 .200 & 2.116 .914 \\
\hline Goianésia do Pará & 1.155 .987 & 1.307 .812 & 1.304 .957 & 1.621 .943 & 2.188 .900 & 2.469 .733 \\
\hline & & & & & & \\
\hline
\end{tabular}

Quadro 7: Estado do Pará: FPM transferidos aos municípios (19952000) (valores em $\mathrm{R} \$ 1$,00).

Fonte: STN. 
No caso específico de Marabá, cabe salientar que, em decorrência da manutenção do volume elevado de sua população (Quadro 2), o seu coeficiente de participação no FPM é o mais elevado $(4,0)$, de acordo com os parâmetros definidos pela Secretaria do Tesouro Nacional (STN) para os municípios do interior. Conseqüentemente, o valor do seu FPM é o mais alto entre os municípios analisados, tendo sido de R\$ 13,8 milhões em 2000.

Para a maior parte dos municípios, o FPM constitui-se na sua principal fonte de receita tributária, visto que o seu valor excede o valor total dos demais tributos arrecadados e transferidos. Isso é mais relevante justamente para os municípios que estão à margem da industrialização no Estado - situação de alguns dos municípios localizados nas regiões do entorno dos grandes empreendimentos. Nesse caso estão os municípios de Terra Santa, Curionópolis, Eldorado dos Carajás, Abaetetuba, Moju, Acará e Baião. Para esses municípios, o FPM chega a representar mais de $80 \%$ dos recursos oriundos dos principais impostos que compõem sua receita total.

\section{IMPACTOS E MUDANÇAS NA ARRECADAÇÃO TRIBUTÁRIA}

No caso dos tributos arrecadados, há também uma diferenciação na arrecadação dos municípios. Com o início de funcionamento das indústrias de grande porte e a contínua expansão da sua produção, um maior volume de produtos é comercializado a cada ano, implicando uma elevada intensidade dos fluxos de circulação de mercadorias no âmbito estadual e deste para o mercado externo, o que resulta no aumento da receita proveniente do Imposto sobre Circulação de Mercadorias e Serviços de Transporte Interestadual e Intermunicipal e de Comunicação (ICMS) e até mesmo do Imposto sobre Produtos Industrializados (IPI). Evidentemente que o aumento da receita desses impostos provocou efeitos redistributivos positivos no Estado como um todo, pois aumentou o valor nominal da cota financeira de cada município, inclusive da parte que corresponde à receita do governo estadual. Só que esse aumento não ocorreu de forma linear, e é aí que reside a diferença básica no contexto sub-regional entre os municípios-sede e os demais das regiões de entorno.

Quando ocorre um maior nível de agregação de valor, isto é, quando as indústrias geram produtos com valor adicionado ${ }^{5}$ em decorrência do

\footnotetext{
${ }^{5}$ De acordo com a Lei Complementar n. ${ }^{\circ}$ 63, de 11 de janeiro de 1990, o valor adicionado corresponde, para cada município, ao valor das mercadorias saídas, acrescido do valor das prestações de serviços, no seu território, deduzido o valor das mercadoria s entradas, em cada ano civil. O Estado apura a relação percentual entre o valor adicionado em cada município e o valor total do Estado, aplicando esse índice no momento da entrega das parcelas do ICMS que cabem aos municípios.
} 
(semi) beneficiamento realizado localmente, maior é o valor de redistribuição do ICMS para os municípios-sede. Portanto, mesmo considerando os efeitos redistributivos do aumento do valor dos impostos vinculados à produção e circulação de mercadorias para todos os municípios, há uma diferenciação na arrecadação tributária entre os municípios que sediam as indústrias e os investimentos infra-estruturais de grande porte e os demais municípios do Estado, da seguinte forma: a) a participação dos municípios-sede na redistribuição dos principais impostos é cada vez maior, em detrimento dos demais municípios do Estado, inclusive de alguns que fazem parte das suas regiões de entorno; b) nesse acréscimo de receita tributária está incluída uma parcela resultante da arrecadação tributária gerada em outros municípios, dado o princípio do valor adicionado.

No caso do IPI, constata-se que os maiores valores de receita transferida e de acréscimos verificados no período correspondem aos municípios-sede (Quadro 8). A receita auferida por Oriximiná, por exemplo, representa mais do que o dobro da receita de todos os municípios da sua região de entorno - em 2000 a sua receita foi de R $\$$ 601 mil, enquanto a dos demais municípios foi de $\mathrm{R} \$ 233$ mil. Por sua vez, no período 1995-2000, a sua receita de IPI triplicou, enquanto a dos demais municípios não chegou a duplicar.

Parauapebas é outro exemplo dessa diferenciação de receitas. Em 1995, a sua receita de IPI era de R 467 mil, tendo subido em 2000 para R\$2,1 milhões - evoluiu numa proporção 4,5 vezes mais. Em termos absolutos, a sua receita é três vezes maior do que o total da receita de todos os demais municípios da sua região de entorno, inclusive de Marabá, de onde se originou. Por sua vez, Parauapebas é o município que tem recebido a maior parte de IPI nos últimos anos do período analisado, tendo inclusive superado o valor da receita de Barcarena e Tucuruí. Isso decorre não somente do volume de minério de ferro explorado pela CVRD na serra dos Carajás, mas também do valor adicionado em conseqüência do beneficiamento primário desse minério. 


\begin{tabular}{|c|c|c|c|c|c|c|}
\hline Municípios & 1995 & 1996 & 1997 & 1998 & 1999 & 2000 \\
\hline Oriximiná & 198.192 & 249.584 & 477.274 & 440.643 & 469.452 & 601.398 \\
\hline Terra Santa & 39.212 & 49.381 & 57.273 & 52.877 & 34.735 & 26.986 \\
\hline Faro & 3.814 & 4.803 & 19.009 & 17.626 & 21.739 & 36.624 \\
\hline Óbidos & 40.610 & 51.141 & 59.182 & 54.640 & 54.676 & 75.175 \\
\hline Curuá & - & - & 13.364 & 12.338 & 15.914 & 23.131 \\
\hline Alenquer & 30.996 & 39.034 & 43.909 & 40.539 & 44.078 & 71.320 \\
\hline Parauapebas & 467.049 & 588.159 & 1.240 .913 & 1.145 .672 & 1.517 .558 & 2.116 .458 \\
\hline Curionópolis & 66.512 & 83.760 & 95.455 & 88.129 & 68.634 & 48.189 \\
\hline Canaã dos Carajás & - & - & 19.091 & 17.626 & 19.126 & 42.406 \\
\hline Água Azul do Norte & 18.300 & 23.045 & 26.727 & 24.676 & 31.828 & 48.189 \\
\hline Marabá & 292.134 & 367.873 & 425.728 & 393.054 & 455.347 & 551.282 \\
\hline Eldorado de Carajás & 11.821 & 14.887 & 19.091 & 17.626 & 26.094 & 36.624 \\
\hline Barcarena & 493.983 & 622.077 & 763.638 & 705.029 & 725.866 & 830.777 \\
\hline Abaetetuba & 60.047 & 75.617 & 97.364 & 89.891 & 85.962 & 100.233 \\
\hline Moju & 29.010 & 36.534 & 42.000 & 38.777 & 43.297 & 53.972 \\
\hline Acará & 29.024 & 36.550 & 42.000 & 38.777 & 37.201 & 48.189 \\
\hline Almeirim & 340.125 & 428.322 & 496.365 & 458.269 & 383.197 & 451.049 \\
\hline Prainha & 15.170 & 19.229 & 21.000 & 19.388 & 25.132 & 44.334 \\
\hline Tucuruí & 817.271 & 1.029 .196 & 1.240 .913 & 1.145 .672 & 922.720 & 934.866 \\
\hline Breu Branco & 39.173 & 49.331 & 55.364 & 51.115 & 67.050 & 82.885 \\
\hline Novo Repartimento & 77.093 & 97.083 & 112.637 & 103.992 & 69.561 & 59.754 \\
\hline Pacajá & 28.763 & 36.221 & 42.000 & 38.777 & 34.588 & 46.261 \\
\hline Baião & 17.242 & 21.703 & 24.818 & 22.913 & 23.210 & 32.768 \\
\hline Goianésia do Pará & 34.406 & 43.327 & 49.637 & 45.827 & 44.277 & 55.899 \\
\hline
\end{tabular}

Quadro 8: Estado do Pará: IPI transferidos aos municípios (1995-2000) (valores em $\mathrm{R} \$ 1,00)$.

Fonte: Sefa-PA.

Nos demais municípios, tem se registrado uma baixa taxa de crescimento (alcançando no máximo a duplicação do valor da receita); em alguns casos, tem ocorrido até mesmo a redução da receita, como é a situação de Terra Santa, Curionópolis, Paragominas e Novo Repartimento.

Uma análise dos dados de ICMS precisa considerar que, em decorrência das informações disponíveis, esse tributo contempla a) os recursos que são transferidos aos municípios, de acordo com os seus índices de participação, assim como os recursos que são arrecadados diretamente nos municípios, b) os índices de participação dos municípios na distribuição deste imposto e c) os valores adicionados nos municípios.

O que se observa, numa primeira visão, é que os valores arrecadados e os valores transferidos aos municípios não são idênticos. Numa relação direta, isso decorre do fato de que, de acordo com o artigo 158, inciso IV, da Constituição Federal, os 25\% do produto da arrecadação do ICMS que pertencem aos municípios devem ser 
creditados conforme os seguintes critérios: 75\%, no mínimo, na proporção do valor adicionado no município ${ }^{6}$, e os 25\% restantes são determinados com base na população, superfície territorial e número de municípios existentes no ano.

Em outras palavras, quanto mais valor adicionado for gerado em um município, maior será a cota-parte do ICMS que retornará a esse mesmo município, independentemente da sua parcela de contribuição para o total do valor do ICMS arrecadado no Estado, visto que a sua participação no rateio de distribuição se dá sobre o total da arrecadação do Estado e não sobre a arrecadação realizada diretamente no seu território. Da mesma forma, quanto maior for a sua superfície territorial e o tamanho da sua população, maior será o seu valor de receita.

Antes de analisar a diferença entre o valor do ICMS arrecadado e o valor transferido para os municípios, é imprescindível que se verifique primeiramente o valor adicionado em cada município (Quadro 9) e, em seguida, o índice de distribuição definido para cada município (Quadro 10), já que é por meio deles que se chega ao resultado final, que é o valor do ICMS que retorna ao município sob a forma de sua receita.

Pelos dados constantes no Quadro 9, verifica-se que o valor adicionado nos municípios-sede é bastante elevado, constituindo-se nos valores mais elevados entre os municípios analisados. Evidentemente que, em decorrência do beneficiamento industrial realizado pelas indústrias de grande porte existentes nos municípios-sede e em função do valor adicionado gerado em Tucuruí pela UHE Tucuruí, o valor adicionado é expressivo nesses municípios. Em qualquer um dos anos constantes no Quadro 9, o somatório do valor adicionado ocorrente nos municípios-sede representa um terço do valor total gerado no Estado, e isso é algo por si só representativo. Mantendose constante esse valor adicionado e aumentando-se o grau de verticalização das indústrias de grande porte no Pará, os municípios-sede teriam uma participação sempre crescente no rateio do ICMS. Isso incidiria não diretamente nos municípios localizados nas suas regiões de entorno, mas em todos os municípios do Estado, incluindo eles próprios.

Quando o valor adicionado de um município, como Barcarena, aumenta progressivamente e, por conta disso, o seu índice de distribuição do ICMS também aumenta, o município confronta-se com todos os demais municípios do Estado, incluindo não somente os do seu

\footnotetext{
${ }^{6}$ A parcela de $75 \%$ do índice é determinada, por sua vez, com base na média geométrica dos índices de participação de cada município no valor adicionado do Estado, apurados nos dois anos civis imediatamente anteriores ao da apuração. Por exemplo, para a determinação do índice de participação do ICMS de um município para o ano de 2000, foi utilizado o valor adicionado de 1997 e 1998, visto que a sua apuração ocorreu em 1999.
} 
entorno, mas também os outros municípios onde não existe um processamento industrial de médio e grande porte e os demais municípios-sede. Isto é, se o índice de participação de um município no valor adicionado do Estado for mais elevado em um determinado período do que em outro município-sede, como em Parauapebas, então a elevação da sua cota-parte do ICMS dar-se-á à custa da diminuição da cota-parte não somente de Parauapebas, mas também de outros municípios cujo índice de crescimento do valor adicionado tem decrescido.

Em 2000, em comparação a 1999, por exemplo, a participação de Barcarena no valor adicionado do Estado passou de 7,3\% para 9,3\%, enquanto a de Parauapebas caiu de 15,3\% para 10,5\%. Nesse caso, como isso se refletirá posteriormente na definição do índice relativo à cota-parte do $\mathrm{ICMS}^{7}$, o aumento da receita do ICMS de Barcarena implicará uma diminuição relativa da receita do ICMS de Parauapebas, e assim sucessivamente.

\begin{tabular}{|l|r|r|r|r|r|}
\hline Faro & 766.376 & 636.287 & 1.120 .770 & 486.101 & 906.794 \\
\hline Óbidos & 8.881 .947 & 13.481 .138 & 18.981 .038 & 17.067 .053 & 28.767 .102 \\
\hline Curuá & 0 & 694.377 & 811.378 & 700.522 & 2.068 .384 \\
\hline Alenquer & 5.162 .184 & 10.810 .995 & 15.885 .542 & 16.839 .544 & 20.753 .938 \\
\hline Parauapebas & 1.083 .103 .441 & 1.203 .536 .284 & 1.214 .807 .509 & 1.681 .472 .534 & 1.433 .505 .361 \\
\hline Curionópolis & 16.627 .365 & 15.623 .676 & 11.262 .375 & 13.046 .839 & 17.313 .624 \\
\hline Canaã dos Carajás & 0 & 8.064 .383 & 9.698 .987 & 23.447 .843 & 32.029 .312 \\
\hline Água Azul do Norte & 7.560 .552 & 9.687 .466 & 11.405 .219 & 15.483 .619 & 31.761 .135 \\
\hline Marabá & 255.146 .966 & 331.200 .251 & 259.969 .476 & 301.778 .442 & 393.716 .379 \\
\hline Eldorado de Carajás & 5.329 .497 & 5.300 .938 & 7.187 .634 & 12.778 .750 & 16.982 .073 \\
\hline Barcarena & 422.181 .094 & 514.167 .787 & 425.105 .931 & 795.693 .737 & 1.277 .944 .326 \\
\hline Abaetetuba & 30.663 .776 & 33.293 .786 & 39.012 .760 & 42.949 .485 & 41.350 .658 \\
\hline Moju & 13.324 .874 & 11.603 .824 & 12.501 .851 & 18.486 .645 & 16.580 .791 \\
\hline Acará & 4.957 .244 & 7.687 .707 & 10.389 .131 & 15.311 .987 & 26.827 .572 \\
\hline Almeirim & 187.619 .565 & 145.707 .010 & 283.652 .233 & 298.714 .413 & 465.671 .611 \\
\hline Prainha & 1.735 .655 & 4.017 .128 & 7.519 .003 & 7.910 .524 & 8.467 .669 \\
\hline Tucuruí & 457.423 .650 & 466.047 .594 & 590.114 .773 & 761.511 .447 & 888.817 .378 \\
\hline Breu Branco & 35.896 .616 & 37.100 .290 & 27.789 .041 & 42.302 .136 & 59.350 .204 \\
\hline Novo Repartimento & 6.552 .864 & 12.037 .539 & 15.096 .311 & 12.612 .822 & 28.311 .589 \\
\hline Pacajá & 2.473 .471 & 5.900 .276 & 8.428 .874 & 9.188 .428 & 12.369 .939 \\
\hline Baião & 931.832 & 4.019 .881 & 3.834 .580 & 6.141 .999 & 7.232 .997 \\
\hline Goianésia do Pará & 10.756 .287 & 14.391 .108 & 16.389 .888 & 25.602 .792 & 35.759 .849 \\
\hline ESTAD0 PARÁ & 7.094 .846 .325 & 8.355 .658 .480 & 8.607 .986 .973 & 10.966 .037 .336 & 13.676 .649 .498 \\
\hline
\end{tabular}

Quadro 9: Estado do Pará: valor adicionado dos municípios (1996-2000) (em $\mathrm{R} \$ 1,00)$.

Fonte: SEFA-PA.

7 Convém não esquecer que esse impacto dar-se-á somente dois anos depois, dadas as regras de definição da cota-parte do ICMS, como salientado na nota anterior. 
Somente de forma indireta, há um efeito sobre os municípios das regiões de entorno, na medida em que o beneficiamento industrial das indústrias de grande porte, em comparação com o que ocorre nos municípios cujos estabelecimentos industriais existentes são de pequeno porte e de caráter tradicional, vai alterando a participação de cada município no rateio da receita desse imposto.

Por sua vez, é importante também não esquecer o impacto causado pela Lei Complementar n. ${ }^{\circ} 087 / 96$ (Lei Kandir) no cálculo do valor adicionado. Essa lei isenta a incidência do ICMS sobre a exportação de produtos primários ou semibeneficiados, mas o município onde se originou essa isenção não perde receita, visto que, no momento da redistribuição desse tributo, computa-se, pela regra do valor adicionado, a parcela que foi isentada na origem. O mesmo ocorre com a energia elétrica de Tucuruí, comercializada fora do Estado, que também sofre isenção do ICMS, por força do artigo 155 da Constituição Federal, Lei Complementar n. ${ }^{\circ}$ 63/90, regulamentado no Estado por meio dos decretos n. ${ }^{\circ} 2.393 / 82$ e n. ${ }^{\circ}$ 263/95. Conseqüentemente, para a inclusão (retorno) desse valor adicional de ICMS, a cota individual dos demais municípios do Estado diminui, atingindo dessa maneira alguns dos que se encontram nas regiões de entorno.

Essas alterações ocorrem conseqüentemente no índice de participação dos municípios no produto de arrecadação do ICMS, a partir do qual se calcula o valor do imposto que cabe a cada município. O Quadro 10 evidencia essas alterações com muita propriedade, no período 1995-2000. Observa-se que os municípios-sede têm aumentado a sua participação relativa de forma significativa, principalmente a partir de 1997, sem que isso implique necessária e diretamente a diminuição da cota-parte dos municípios das regiões de entorno.

$\mathrm{Na}$ verdade, alguns municípios, como Faro, Canaã dos Carajás, Eldorado dos Carajás, Goianésia do Pará, Breu Branco e Acará, também aumentaram o seu índice de participação no período; em contrapartida, outros municípios, como Terra Santa, Curionópolis, Paragominas e Novo Repartimento, diminuíram a sua participação. O município de Tucuruí, onde se localiza um empreendimento de grande porte, também diminuiu a sua cota-parte nesse período. Isso evidencia uma espécie de corrida na qual todo ano os municípios competem por uma melhor participação no ranking dos primeiros colocados, só que aqueles que possuem uma estrutura de transformação industrial mais significativa (nem que seja baseada em apenas uma unidade, mas de grande porte) sempre chegam na frente e conseguem os melhores prêmios. 


\begin{tabular}{|c|c|c|c|c|}
\hline \multirow[b]{2}{*}{ Municípios } & \multicolumn{4}{|c|}{ Índice para os anos de } \\
\hline & 1995 e 1996 & $\begin{array}{c}\text { 1997/1998 e } \\
\text { jan.-jun. } 1999\end{array}$ & jul. a dez. 1999 & 2000 \\
\hline Oriximiná & 1,5173 & 2,5 & 3,15 & 3,12 \\
\hline Terra Santa & 0,3002 & 0,3 & 0,13 & 0,14 \\
\hline Faro & 0,0292 & 0,1 & 0,16 & 0,19 \\
\hline Óbidos & 0,3109 & 0,31 & 0,35 & 0,39 \\
\hline Curuá & - & 0,07 & 0,12 & 0,12 \\
\hline Alenquer & 0,2373 & 0,23 & 0,3 & 0,37 \\
\hline Parauapebas & 3,5756 & 6,5 & 11,6 & 10,98 \\
\hline Curionópolis & 0,5092 & 0,5 & 0,34 & 0,25 \\
\hline Canaã dos Carajás & - & 0,1 & 0,13 & 0,22 \\
\hline Água Azul do Norte & 0,1401 & 0,14 & 0,24 & 0,25 \\
\hline Marabá & 2,2365 & 2,23 & 3,23 & 2,86 \\
\hline Eldorado dos Carajás & 0,0905 & 0,1 & 0,21 & 0,19 \\
\hline Barcarena & 3,7818 & 4 & 4,75 & 4,31 \\
\hline Abaetetuba & 0,4597 & 0,51 & 0,53 & 0,52 \\
\hline Moju & 0,2221 & 0,22 & 0,3 & 0,28 \\
\hline Acará & 0,2222 & 0,22 & 0,23 & 0,25 \\
\hline Almeirim & 2,6039 & 2,6 & 2,07 & 2,34 \\
\hline Prainha & 0,1169 & 0,11 & 0,19 & 0,23 \\
\hline Tucuruí & 6,2568 & 6,5 & 4,77 & 4,85 \\
\hline Breu Branco & 0,2999 & 0,29 & 0,51 & 0,43 \\
\hline Novo Repartimento & 0,5902 & 0,59 & 0,27 & 0,31 \\
\hline Pacajá & 0,2202 & 0,22 & 0,2 & 0,24 \\
\hline Baião & 0,132 & 0,13 & 0,15 & 0,17 \\
\hline Goianésia do Pará & 0,2634 & 0,26 & 0,28 & 0,29 \\
\hline
\end{tabular}

Quadro 10: Estado do Pará: índice de participação dos municípios no produto de arrecadação do ICMS (1995-2000).

Fonte: SEFA-PA.

Entre os municípios analisados, o município de Parauapebas tem alcançado repetidamente o primeiro lugar no pódio (sendo superado apenas por Belém, a capital do Estado, que tem perdido posição a cada ano): aumentou a sua cota-parte de 3,57\% para 10,98\% entre 1995 e 2000, ou seja, triplicou a sua participação. Oriximiná, em seguida, conseguiu duplicar a sua participação no período, tendo evoluído de 1,51\% para 3,12\%; Barcarena também tem expandido a sua participação, que passou de 3,78\% para 4,31\%.

Embora Almeirim e Tucuruí tenham perdido posições no período, pode-se inferir que as empresas com participação acionária da CVRD têm contribuído decisivamente para a) expandir a receita total de arrecadação do ICMS, beneficiando assim os entes federados, Estado e municípios como um todo, b) alterar a participação dos municípios no rateio do ICMS, propiciando benefícios sobretudo para os municípios-sede, e c) tornar 
esse tributo a principal fonte de receita desses municípios. Isso tem contribuído para que o Estado dê um tratamento especial e diferenciado à CVRD, predominando uma relação de dependência mútua, passando o Estado a vincular a sua estratégia de desenvolvimento à eficácia dos investimentos realizados por essa empresa.

O resultado desses condicionantes sobre a arrecadação e a transferência do ICMS para os municípios encontra-se evidenciado no Quadro 11. Observa-se que há uma clara diferenciação entre esses dois tipos de receita, existindo dois diferentes grupos de municípios entre os analisados neste trabalho: os que recebem a mais do que contribuem para o produto do ICMS e os que recebem a menos do que contribuem para a formação da receita do ICMS. Em cada um dos grupos encontramse tanto os municípios-sede quanto os municípios das regiões de entorno.

Na região polarizada por Oriximiná, todos os municípios receberam transferência do ICMS em valores acima da sua real contribuição; no caso específico de Oriximiná, isso ocorreu somente entre 1997 e 1998, invertendo-se a situação nos demais anos. O município de Parauapebas vinha recebendo o maior valor desde 1997, entretanto, com a incidência da Lei Kandir ${ }^{8}$, diminuiu proporcionalmente a sua arrecadação. Isso demonstra de forma bastante evidente que a diferença a maior (que muito provavelmente não seria tão significativa caso não houvesse a isenção desse tributo) dá-se à custa da receita dos demais municípios do Estado. Essa diferença tem evoluído a taxas crescentes a cada ano, tendo superado, em 2000, 3,5 vezes o valor da arrecadação registrada (R\$19,9 milhões). Os demais municípios dessa região que também têm obtido uma receita a maior são Curionópolis, Canaã dos Carajás e Água Azul do Norte. O município de Marabá, em situação contrária, é um dos que contribuem mais do que recebem, de forma ininterrupta, tendo sido a sua diferença a menor, em 2000, mais de 60\% (R\$ 11 milhões).

Na região de Barcarena, não há propriamente um município recebendo a mais, de forma continuada. Na verdade, poder-se-ia dizer que, nessa região, praticamente todos perdem recursos. O caso mais gritante é justamente o de Barcarena, que tem contribuído com valores bem expressivos, mas sua receita do ICMS é inexpressiva, na proporção de 3 para 1, respectivamente, em 2000 (diferença a menor de $\mathrm{R} \$ 24,8$ milhões). Para que haja uma reversão dessa situação, torna-se necessário o aumento da verticalização da produção industrial ali ocorrente, o que, sem dúvida, provocará uma nova alteração nos índices de todos os demais municípios paraenses.

\footnotetext{
${ }^{8}$ Entrou em vigência, no mês de setembro de 1996, a LC-87, que isenta ICMS sobre exportações, o que representa uma perda estimada de 14\% da receita tributária própria do Estado. Em decorrência dessa lei, alguns municípios apresentaram uma queda expressiva na arrecadação.
} 


\begin{tabular}{|c|c|c|c|c|c|c|c|c|c|c|c|c|}
\hline \multirow{2}{*}{ Municípios } & \multicolumn{6}{|c|}{ Arrecadação de ICMS } & \multicolumn{6}{|c|}{ Transferência de ICMS } \\
\hline & 1995 & $1996^{*}$ & 1997 & 1998 & 1999 & 2000 & 1995 & 1996 & 1997 & 1998 & 1999 & 2000 \\
\hline Oriximiná & 13.633 .085 & 9.661 .816 & 3.370 .865 & 3.766 .721 & 8.665 .129 & 12.165 .365 & 2.404 .264 & 2.789 .780 & 4.189 .564 & 4.282 .336 & 5.491 .346 & 7.856 .592 \\
\hline Terra Santa & 21.144 & 25.270 & 25.827 & 40.133 & 25.493 & 18.267 & 475.678 & 551.962 & 502.748 & 513.880 & 394.518 & 352.539 \\
\hline Faro & 3.140 & 2.944 & 1.271 & 4.683 & 1.160 & 2.151 & 46.269 & 53.689 & 167.583 & 171.293 & 255.908 & 478.446 \\
\hline Óbidos & 380.203 & 383.155 & 374.383 & 489.502 & 606.596 & 689.106 & 492.642 & 571.636 & 519.506 & 531.010 & 637.635 & 982.074 \\
\hline Curuá & - & 337 & 387 & 1.863 & 919 & 852 & - & - & 117.308 & 119.905 & 187.666 & 302.177 \\
\hline Alenquer & 233.355 & 201.494 & 261.615 & 212.891 & 305.631 & 350.460 & 376.018 & 436.311 & 385.440 & 393.975 & 516.080 & 931.711 \\
\hline Parauapebas & 47.314 .014 & 34.038 .479 & 3.928 .516 & 4.662 .430 & 4.619 .384 & 7.736 .216 & 5.665 .780 & 6.574 .268 & 10.892 .867 & 11.134 .072 & 17.413 .590 & 27.649 .159 \\
\hline Curionópolis & 211.573 & 645.664 & 435.931 & 351.052 & 537.762 & 728.201 & 806.862 & 936.239 & 837.913 & 856.467 & 789.041 & 629.535 \\
\hline Canaã dos Carajás & - & 39 & 42.538 & 50.224 & 242.634 & 167.694 & - & - & 167.583 & 171.293 & 223.919 & 553.990 \\
\hline Água Azul do Norte & 47.030 & 231.389 & 221.664 & 332.510 & 367.924 & 268.856 & 221.998 & 257.595 & 234.616 & 239.811 & 375.332 & 629.535 \\
\hline Marabá & 21.336 .211 & 23.611 .370 & 14.310 .658 & 10.833 .921 & 10.821 .824 & 18.561 .504 & 3.553 .885 & 4.112 .135 & 3.737 .091 & 3.819 .483 & 5.346 .341 & 7.201 .876 \\
\hline Eldorado de Carajás & 378.084 & 299.275 & 435.387 & 514.971 & 1.143 .672 & 1.564 .043 & 143.403 & 166.398 & 167.583 & 171.293 & 309.223 & 478.446 \\
\hline Barcarena & 22.249 .491 & 20.376 .323 & 6.528 .817 & 6.346 .214 & 15.744 .146 & 35.625 .721 & 5.992 .518 & 6.953 .397 & 6.703 .303 & 6.851 .737 & 8.476 .925 & 10.853 .176 \\
\hline Abaetetuba & 1.470 .126 & 1.848 .937 & 1.367 .187 & 1.320 .802 & 1.190 .500 & 1.304 .457 & 728.426 & 845.226 & 854.671 & 873.596 & 1.000 .169 & 1.309 .432 \\
\hline Moju & 901.969 & 1.139 .142 & 1.813 .504 & 1.114 .449 & 842.848 & 1.387 .192 & 351.933 & 408.364 & 368.682 & 376.846 & 507.550 & 705.079 \\
\hline Acará & 1.213 .833 & 824.633 & 1.125 .195 & 594.991 & 442.435 & 374.456 & 352.091 & 408.548 & 368.682 & 376.846 & 532.909 & 629.535 \\
\hline Almeirim & 7.755 .145 & 6.506 .462 & 1.735 .903 & 1.370 .748 & 3.597 .859 & 5.343 .827 & 4.126 .055 & 4.787 .654 & 4.357 .147 & 4.453 .629 & 4.425 .039 & 5.892 .444 \\
\hline Prainha & 28.188 & 33.277 & 16.890 & 26.212 & 25.124 & 11.667 & 185.236 & 214.938 & 184.341 & 188.423 & 296.427 & 579.172 \\
\hline Tucuruí & 9.986 .358 & 6.790 .360 & 4.807 .884 & 16.864 .407 & 21.229 .444 & 24.310 .547 & 9.914 .322 & 11.504 .050 & 10.892 .867 & 11.134 .072 & 10.630 .744 & 12.212 .971 \\
\hline Breu Branco & 2.895 .405 & 3.560 .764 & 2.005 .459 & 1.537 .370 & 1.657 .990 & 2.629 .072 & 475.212 & 551.410 & 485.989 & 496.751 & 791.183 & 1.082 .799 \\
\hline Novo Repartimento & 561.830 & 590.650 & 587.397 & 541.685 & 579.829 & 1.313 .447 & 935.212 & 1.085 .170 & 988.737 & 1.010 .631 & 791.170 & 780.623 \\
\hline Pacajá & 90.278 & 90.656 & 195.513 & 120.528 & 85.649 & 288.370 & 348.922 & 404.870 & 368.682 & 376.846 & 400.920 & 604.353 \\
\hline Baião & 31.473 & 56.757 & 88.698 & 60.888 & 385.821 & 169.882 & 209.193 & 242.702 & 217.857 & 222.682 & 270.835 & 428.084 \\
\hline Goianésia do Pará & 1.262 .526 & 1.796 .483 & 1.816 .878 & 2.276 .362 & 2.604 .350 & 3.664 .766 & 417.375 & 484.300 & 435.715 & 445.363 & 520.344 & 730.260 \\
\hline
\end{tabular}

Quadro 11: Estado do Pará: receita de ICMS por municípios versus transferência de ICMS para os municípios, 1995-2000 (valores em R\$ 1,00).

Fonte: SEFA-PA. 
Na região de abrangência de Almeirim, tanto esse município quanto o de Prainha têm recebido uma receita do ICMS a maior ao longo do período. As situações, porém, são distintas: em Prainha a arrecadação do ICMS tem diminuído, mas a sua transferência tem aumentado a taxas crescentes; já em Almeirim, tanto a arrecadação quanto a transferência do ICMS têm exibido taxas decrescentes a cada ano. Isso resulta da perda de importância do complexo industrial do Jari na economia do Estado.

Na região de Tucuruí, apenas os municípios de Breu Branco e o de Goianésia do Pará recebem ICMS menor em comparação à arrecadação realizada. Especificamente no caso de Tucuruí, a diferença é de cerca de 50\%, o que implica dizer que, se não houvesse isenção desse tributo para a energia elétrica comercializada fora do Estado, essa diferença seria ainda maior.

Essa realidade, evidentemente, sugere a noção de uma suposta perda para o município na medida em que, na verdade, a sua receita (retorno) efetiva do ICMS é bem maior do que se não existisse um empreendimento do porte e da importância do que existe em seu território. Em outras palavras, a existência de um empreendimento de infra-estrutura importante (como a UHE Tucuruí) ou de uma indústria de grande porte (como a Albras e o Projeto Ferro-Carajás) propicia diretamente ao município uma receita do ICMS que, além de ser expressiva em magnitude de valor, jamais seria alcançada pelos estabelecimentos industriais tradicionais ali existentes. Portanto, esse adicional de receita (embora a menor) constituise em ganho para o município, e não propriamente em perda.

Pode-se assim afirmar, em resumo, que, na mesma medida em que a entrada em operação desses empreendimentos de grande porte beneficiou o Estado e os municípios como um todo, em termos de receita tributária, implicou uma alteração significativa na receita tributária desses entes federados, constituindo, no caso dos municípios, um ganho em termos de magnitude de valor absoluta, mas determinando situações diferenciadas em termos de magnitude de valor relativa. Houve evidentemente um efeito mais favorável na arrecadação tributária dos municípios-sede, mas isso só afeta os municípios das regiões de entorno de forma indireta.

\section{AUTONOMIA FINANCEIRA E CAPACIDADE DE INVESTIMENTO}

O adicional de receita obtido pelos municípios-sede não lhes garante de forma linear uma relativa autonomia financeira e uma capacidade de investimento significativa. Essa situação é mais crítica quando se verifica o caso dos municípios das regiões de entorno. Da análise do Quadro 12 - que demonstra a receita total e a despesa total 


\begin{tabular}{|c|c|c|c|c|c|c|c|c|c|c|}
\hline \multirow[b]{2}{*}{ Municípios } & \multicolumn{4}{|c|}{ Receitas } & \multicolumn{6}{|c|}{ Despesas } \\
\hline & $\begin{array}{l}\text { Receitas } \\
\text { próprias }\end{array}$ & $\begin{array}{c}\text { Receitas } \\
\text { transferidas }\end{array}$ & $\begin{array}{l}\text { Outras } \\
\text { receitas }\end{array}$ & TOTAL & $\begin{array}{l}\text { Despesas } \\
\text { de custeio }\end{array}$ & $\begin{array}{c}\text { Transferências } \\
\text { correntes }\end{array}$ & Investimentos & $\begin{array}{c}\text { Inversões } \\
\text { financeiras }\end{array}$ & $\begin{array}{c}\text { Transferências } \\
\text { de capital }\end{array}$ & TOTAL \\
\hline Oriximiná & 2.259 & 27.761 & 361 & 30.381 & 21.088 & 687 & 9.121 & 52 & 244 & 31.192 \\
\hline Terra Santa* & 49 & 5.435 & 9 & 5.493 & 4.587 & 48 & 799 & - & 74 & 5.508 \\
\hline Faro & 30 & 3.456 & 12 & 3.498 & 2.734 & 516 & 256 & - & 74 & 3.580 \\
\hline Óbidos* & 332 & 12.599 & 164 & 13.095 & 11.312 & 530 & 1.124 & 5 & 121 & 13.092 \\
\hline Curuá & 38 & 2.752 & 17 & 2.807 & 2.083 & 24 & 841 & - & 3 & 2.951 \\
\hline Alenquer & 231 & 11.781 & 34 & 12.046 & 8.169 & 807 & 1.254 & 3 & 239 & 10.472 \\
\hline Parauapebas & 6.766 & 58.162 & 17.445 & 82.373 & 19.071 & 20.993 & 32.316 & 222 & 2.407 & 75.009 \\
\hline Curionópolis* & 516 & 8.774 & 5 & 9.295 & 6.056 & 77 & 1.232 & - & 30 & 7.395 \\
\hline Canaã dos Carajás** & 28 & 1.498 & 1 & 1.527 & 1.151 & 10 & 208 & - & - & 1.369 \\
\hline Água Azul do Norte & 83 & 6.935 & - & 7.018 & 4.306 & 64 & 2.295 & - & 53 & 6.718 \\
\hline Marabá**** & 2.300 & 37.695 & 499 & 40.494 & 24.464 & 2.495 & 8.017 & 69 & 240 & 35.285 \\
\hline Eldorado dos Carajás & 8 & 6.413 & 942 & 7.363 & 6.184 & 238 & 1.583 & - & - & 8.005 \\
\hline Barcarena & 3.793 & 24.615 & 55 & 28.463 & 20.699 & 1.435 & 2.424 & - & - & 24.558 \\
\hline Abaetetuba* & 656 & 25.334 & 101 & 26.091 & 21.968 & 1.123 & 2.750 & - & 135 & 25.976 \\
\hline Mojú & 151 & 12.496 & 339 & 12.986 & 6.977 & 129 & 2.033 & 99 & 48 & 9.286 \\
\hline Acará & 344 & 13.720 & 770 & 14.834 & 10.843 & 614 & 2.457 & - & 76 & 13.990 \\
\hline Almeirim* & 1.833 & 20.976 & 105 & 22.914 & 20.840 & 820 & 889 & - & 271 & 22.820 \\
\hline Prainha & 16 & 9.000 & 31 & 9.047 & 6.348 & 1.068 & 1.974 & - & 42 & 9.432 \\
\hline Tucuruí** & 506 & 22.117 & 4.871 & 27.494 & 22.501 & 1.688 & 3.893 & 836 & 1.560 & 30.478 \\
\hline Breu Branco & 200 & 10.260 & 584 & 11.044 & 6.805 & 194 & 2.779 & - & 48 & 9.826 \\
\hline Novo Repartimento* & 370 & 21.637 & 115 & 22.122 & 15.811 & 382 & 4.826 & 96 & 116 & 21.231 \\
\hline Pacajá ${ }^{* * * *}$ & 21 & 3.672 & 4 & 3.697 & 2.650 & 61 & 801 & - & 30 & 3.542 \\
\hline Baião* & 142 & 7.519 & 40 & 7.701 & 6.821 & 171 & 431 & 6 & 81 & 7.510 \\
\hline Goianésia do Pará* & 244 & 11.539 & 57 & 11.840 & 10.042 & 157 & 1.506 & 118 & 98 & 11.921 \\
\hline
\end{tabular}

Quadro 12: Estado do Pará: receitas e despesas realizadas, por município, 2000 (valores em R\$ 1.000,00).

Fonte: TCM-PA.

Referente ao ano de $\left(^{*}\right)$ 2001, $\left(^{* *}\right) 1997,\left(^{* * *}\right) 1998$ e $\left(^{* * * *}\right) 1996$. 
de cada município, de forma desagregada pelos seus principais elementos componentes $^{9}$-, infere-se que, na ótica da receita, os municípios-sede são os que apresentam os maiores percentuais de receita própria no contexto da sua receita total, muito embora esse percentual não ultrapasse 10\%, com exceção do município de Barcarena, que atingiu 13,3\% em 2000.

De forma geral, todos os municípios analisados - análise que retrata de per se a realidade dos municípios paraenses - sobrevivem basicamente de receitas oriundas de transferências governamentais (constitucionais e voluntárias), que representam mais de 90\% de suas receitas totais. Os municípios de Terra Santa, Faro, Eldorado dos Carajás e Prainha - localizados no entorno dos municípios-sede - são exemplos de situações em que a receita própria praticamente não existe, pois as receitas transferidas representam mais de 99\%, ou seja, a quase totalidade de suas receitas totais. O que diferencia esses dois conjuntos de municípios é que, nos municípios-sede, os empreendimentos produtivos ou infra-estruturais de grande porte propiciaram uma expressiva receita oriunda da prestação de serviços (ISS) - ao contrário do que se observa nos municípios do entorno. Além do mais, nos municípios-sede, quase sempre o IPTU é cobrado, enquanto nos demais esse tributo é geralmente ignorado.

$\mathrm{Na}$ ótica da despesa, verifica-se que quase todos os municípios têm sua receita basicamente comprometida com as despesas de custeio - folha de pessoal e encargos sociais, serviços prestados e aquisição de material de consumo -, que representam entre $70 \%$ e $90 \%$ de suas despesas totais. A exceção fica por conta de Parauapebas, que direcionou $25 \%$ de sua despesa total para esse tipo de despesa. Isso permitiu que esse município apresentasse em 2000 as maiores taxas na rubrica de investimento, principalmente no que diz respeito ao elemento de despesa Obras e Instalações. Os municípios de Faro, Óbidos e Baião (municípios do entorno), assim como Barcarena e Almeirim (municípios-sede), foram os que menos fizeram investimentos (abaixo de 10\%). Daí,

\footnotetext{
${ }^{9}$ Devido ao volume de informações constantes no Tribunal de Contas dos Municípios (TCM) do Estado do Pará, e considerando que este artigo analisa conjuntamente a situação de 29 municípios, optou-se por apresentar os dados de Receita e Despesa relativos apenas a um ano de referência, no caso o ano de 2000, por ser mais representativo da situação atual das finanças municipais. Esses dados ainda não se encontram totalmente consolidados (aprovados) pelo TCM-PA, mas podem ser utilizados para conferência pela sociedade em geral, visto que já passaram por uma análise prévia pela equipe técnica do referido tribunal. No caso da impossibilidade de obtenção dos dados para o ano de referência, adotou-se o ano mais próximo e em disponibilidade na Internet, no período de 1996 a 2001.
} 
evidentemente, a elevada despesa com a estrutura administrativa do poder municipal.

Por conseguinte, a capacidade de investir em equipamentos urbanos (hospitais, escolas etc.), o estímulo a atividades produtivas e a capacitação de pessoal não ocorrem linearmente em todos os municípiossede, nem tampouco nos municípios periféricos das regiões de entorno. Para tanto, é necessário que se reduzam as despesas com a manutenção da máquina administrativa ou, em outras palavras, que se aumente a eficácia administrativa do poder municipal. A possibilidade de transferência de recursos em montante significativo para investimento produtivo e social só se mostra possível nos municípios-sede, dada a magnitude de suas receitas, o que faz com que alguns dos municípios periféricos careçam de sustentação financeira, tendo, portanto, pouca ou quase nenhuma condição de gerenciar o próprio destino e o futuro de sua população.

\section{IMPACTOS NA ÁREA SOCIAL}

Uma das metas importantes deste trabalho é a identificação de correlações entre o desenvolvimento econômico-financeiro diferenciado dos municípios e os índices de desenvolvimento humano (IDH) municipal criados pelo Programa das Nações Unidas para o Desenvolvimento (PNUD), em 1990. Esse índice resulta da combinação de três componentes básicos do desenvolvimento: a longevidade, medida pela expectativa de vida ao nascer; a educação, medida por uma combinação da taxa de alfabetização de adultos com a taxa agregada de matrícula nos níveis de ensino fundamental, médio e superior; a renda, medida pelo poder de compra da população baseado no PIB per capita (ver PNUD/IPEA, 1997). O índice-síntese de desenvolvimento é, portanto, uma combinação desses três índices, que variam de 0 a 1, isto é, quanto mais próximo de 1 o valor desse indicador, maior será o nível de desenvolvimento do município considerado.

O exame do IDH dos municípios-sede de grandes empresas ou situados nas periferias dos grandes projetos mínero-metalúrgicos e de energia elétrica implantados a partir da década de 70 (Quadro 13) revela diferenças no estímulo às atividades produtivas, na distribuição de equipamentos urbanos, no acesso às informações, no emprego e, portanto, no dinheiro. Essas variáveis refletem seguramente no índice de desenvolvimento humano de cada município.

Da análise do IDH-M relativo a 1970, período anterior à implantação das empresas na Amazônia, deduz-se que existe reduzida diferenciação 
nos valores apresentados pelos diversos municípios estudados. Quanto aos dados relativos a 1980 e a 1991, verifica-se que os municípios-sede do projeto Jarí (Almeirim), da CVRD (Marabá) e da Eletronorte (Tucuruí) apresentaram valores superiores aos índices exibidos pelos municípios situados em seus arredores. Embora no geral esses dados resultem de uma melhora nos índices de longevidade e de educação, os valores maiores correspondem ao indicador de renda, expressando o aumento local no número de empregos. Todavia, os valores relativos à renda foram mais elevados em 1980 do que em 1991, quando a maioria dos projetos já tinha sido implantada. Nesses anos, o principal destaque nos valores de IDH-M relaciona-se com os municípios situados no arco ParauapebasMarabá-Tucuruí.

Uma questão importante não pode deixar de ser levantada: esses dados, particularmente no caso dos municípios-sede, escondem as diferenciações internas a cada município. Os índices de desenvolvimento humano são, certamente, exagerados pela presença das company-towns, nas quais as condições de vida são superiores às da cidade normal e de seus distritos. De qualquer forma, esses municípios apresentam situações financeiras privilegiadas, resultantes não só, mas principalmente, dos recursos gerados pelos royalties (CFEM). Trata-se de uma conquista da Constituição de 1988 que, no entanto, não beneficia os municípios do entorno dos municípios-sede. 


\begin{tabular}{|c|c|c|c|c|c|c|c|c|c|c|c|c|}
\hline MUNICÍPIO & \multicolumn{2}{|c|}{ IDH-M } & \multicolumn{4}{|c|}{ IDH-M LONGEVIDADE } & \multicolumn{3}{|c|}{ IDH-M EDUCAÇÃO } & \multicolumn{3}{|c|}{ IDH-M RENDA } \\
\hline & 1970 & 1980 & 1991 & 1970 & 1980 & 1991 & 1970 & 1980 & 1991 & 1970 & 1980 & 1991 \\
\hline Barcarena & 0,363 & 0,472 & 0,631 & 0,452 & 0,530 & 0,660 & 0,441 & 0,501 & 0,631 & 0,196 & 0,383 & 0,601 \\
\hline Abaetetuba & 0,364 & 0,506 & 0,512 & 0,460 & 0,595 & 0,669 & 0,440 & 0,454 & 0,525 & 0,193 & 0,469 & 0,343 \\
\hline Moju & 0,319 & 0,448 & 0,433 & 0,452 & 0,533 & 0,607 & 0,362 & 0,398 & 0,410 & 0,145 & 0,412 & 0,281 \\
\hline Acará & 0,281 & 0,387 & 0,487 & 0,439 & 0,533 & 0,586 & 0,272 & 0,323 & 0,399 & 0,133 & 0,306 & 0,477 \\
\hline Oriximiná & 0,356 & 0,540 & 0,560 & 0,434 & 0,575 & 0,623 & 0,433 & 0,492 & 0,616 & 0,200 & 0,554 & 0,441 \\
\hline Faro & 0,375 & 0,470 & 0,497 & 0,431 & 0,518 & 0,689 & 0,513 & 0,556 & 0,593 & 0,181 & 0,335 & 0,209 \\
\hline Óbidos & 0,365 & 0,471 & 0,502 & 0,418 & 0,507 & 0,611 & 0,531 & 0,537 & 0,573 & 0,146 & 0,370 & 0,321 \\
\hline Alenquer & 0,350 & 0,438 & 0,469 & 0,422 & 0,542 & 0,593 & 0,440 & 0,460 & 0,538 & 0,190 & 0,312 & 0,276 \\
\hline Parauapebas & & & 0,601 & & & 0,551 & & & 0,574 & & & 0,680 \\
\hline Curionópolis & & & 0,512 & & & 0,551 & & & 0,450 & & & 0,537 \\
\hline Marabá & 0,325 & 0,645 & 0,563 & 0,361 & 0,513 & 0,551 & 0,373 & 0,476 & 0,594 & 0,241 & 0,945 & 0,544 \\
\hline Almeirim & 0,374 & 0,684 & 0,632 & 0,402 & 0,601 & 0,699 & 0,379 & 0,528 & 0,562 & 0,343 & 0,923 & 0,636 \\
\hline Prainha & 0,369 & 0,487 & 0,463 & 0,462 & 0,540 & 0,662 & 0,439 & 0,435 & 0,494 & 0,208 & 0,485 & 0,234 \\
\hline Tucuruí & 0,365 & 0,677 & 0,544 & 0,392 & 0,452 & 0,580 & 0,497 & 0,625 & 0,570 & 0,205 & 0,954 & 0,481 \\
\hline Pacajá & & & 0,416 & & & 0,664 & & & 0,373 & & & 0,211 \\
\hline Baião & 0,340 & 0,465 & 0,457 & 0,383 & 0,497 & 0,609 & 0,480 & 0,525 & 0,554 & 0,157 & 0,374 & 0,208 \\
\hline
\end{tabular}

Quadro 13: Índice Municipal de Desenvolvimento Humano (IDH-M) de alguns municípios do Estado do Pará em 1970, 1980 e 1991.

Fonte: IPEA e PNUD. 


\section{PERSPECTIVAS FUTURAS: A TÍTULO DE CONSIDERAÇÕES FINAIS}

Propusemo-nos, neste trabalho, a examinar os desequilíbrios sociais e econômico-financeiros dos municípios paraenses e amapaenses, direta ou indiretamente afetados pelo processo de reestruturação do espaço, particularmente acelerado pela combinação de políticas públicas destinadas a favorecer a atração de investimentos voltados para a implantação de atividades de extração e transformação industriais de commodities minerais, em especial a partir dos governos militares. Seguindo-se a orientação governamental, pautou-se a lógica nacional/ regional pela global (isto é, tecida em função dos interesses de empresas globais unidas às nacionais por meio de joint ventures), o que teve como resultado a reestruturação territorial na Amazônia oriental.

Nosso interesse-guia foi tentar investigar como as situações de desigualdades evoluíram e tentar compreender a polarização cidades e municípios relativamente ricos e cidades e municípios pobres. Tal polarização explica-se pelas dinâmicas locais diferenciadas que se configuram a partir dos pólos de crescimento econômico (organizados em torno das minas, das fontes energéticas, das vias de circulação e dos portos) e a partir das áreas ao redor desses pólos. Tais periferias caracterizam-se pela reduzida capacidade interna de geração de recursos e pelos reduzidos investimentos públicos. Isso ocorre não obstante a exacerbação da problemática social nas periferias em decorrência dos intensos movimentos migratórios, atraídos particularmente pelas políticas de estímulo aos projetos mínero-metalúrgicos.

A teoria da polarização atribuiu um papel dinamizador à cidade ou à sede do município, que abriga uma usina de energia ou atividades industriais. Por exemplo, Marabá, Tucuruí, Oriximiná e Almeirim, cidades ribeirinhas, tradicionalmente estruturadoras da produção agrícola na primeira metade do século XX, foram revitalizadas e reestruturadas a partir dos projetos infra-estruturais e produtivos da década de 70. Mesmo Parauapebas, uma cidade que surgiu posteriormente no entorno da área da CVRD na serra de Carajás, adquiriu a função de pólo regional, sem todavia, pelo menos até 2000, diminuir a importância de Marabá, originalmente pensada como o pólo por excelência do Sudeste do Pará. Diferentemente das cidades mineiras, Marabá (que perdeu a mina de Carajás com a criação de Parauapebas) e Barcarena transformaram-se em centros de produção industrial por excelência, beneficiando-se de suas respectivas vantagens locacionais. A primeira localiza-se em áreanódulo de redes viárias (fluviais, rodoviárias e ferroviárias), de energia 
e de informação. A segunda, Barcarena, por se localizar em uma área portuária que cresceu com a exportação do alumínio, poderá tornar-se um centro industrial ainda mais próspero, caso o governo estadual encontre uma forma de estimular a diversificação produtiva no Estado.

Os municípios-sede de empresas e suas respectivas cidades constituíram, conforme já descrito, pólos populacionais que extrapolaram o âmbito local/municipal. A desigualdade espacial entre os municípios dos estados do Pará e Amapá, resultado da estruturação dos municípios promovida pela implantação em seus espaços de empresas de extração e de transformação da matéria-prima, pôde ser inferida dos dados de transferência de valores e de arrecadação de tributos concernentes ao período de 1995 a 2000. Em particular, a maior capacidade que têm os municípios onde estão instaladas grandes empresas de gerar recursos tributários, compatíveis com as demandas sociais e com as necessidades de "modernização" da estrutura produtiva, tendeu a ampliar o quadro de desigualdade econômico-financeira entre municípios. Tal desigualdade não tem sido, de maneira alguma, compensada pelos recursos, como os oriundos do Fundo de Participação dos Municípios (FPM), cuja finalidade é diminuir as diferenciações entre municípios do mesmo Estado, provocando uma redistribuição dos recursos por meio da transferência de recursos, fundamentada, no caso do FPM, no volume de população existente em cada um dos municípios.

Contemporaneamente, é possível constatar que o que continua em jogo para os estados e municípios é, de um lado, o desafio da manutenção da capacidade de crescimento auto-sustentável dos municípios e das cidades-pólo e, de outro lado, a viabilidade financeira daqueles classificados como periféricos ou pobres, criados há menos de dez anos. Tudo isso implica preservar a capacidade de arrecadação de uns e, ao mesmo tempo, elevar a capacidade de arrecadação de outros.

Tomando-se como referência a herança recente deixada pelas políticas de pólos e outras a elas associadas e a perspectiva atual das políticas de eixo de integração e desenvolvimento apresentadas pelo governo federal e imitadas pelos governos estaduais, pode-se inferir que o futuro da Amazônia Oriental parece apontar para o crescimento econômico particular dos municípios situados em dois eixos: o eixo formado pela Estrada de Ferro Carajás e o eixo da hidrovia do AraguaiaTocantins. Esses eixos tendem a concentrar ainda mais as facilidades localmente acumuladas nos últimos trinta anos graças às redes de energia, às redes viárias e de circulação de informações, reforçando uma lógica de criação de vantagens competitivas caras às empresas globais e às nacionais a elas associadas. 
Finalmente, é possível afirmar que os temas relativos à reestruturação socioespacial e às desigualdades econômico-financeiras e sociais dos municípios na Amazônia Oriental deverão ser por muito tempo recorrentes na literatura sobre a região. Isso se justifica pelo fato de que governo federal e governos estaduais continuam a fundamentar suas políticas públicas (internas e internacionais) em modelos de "modernização" que privilegiam setores particulares e reforçam a concentração das condições favoráveis à expansão econômica em pontos ou eixos do território mais propícios ao desenvolvimento das potencialidades competitivas das empresas nacionais e internacionais. 


\section{REFERÊNCIAS}

ACSELRAD, H. Eixos de articulação territorial e sustentabilidade do desenvolvimento no Brasil. Rio de Janeiro: Projeto Brasil Sustentável e Democrático, Fase, 2001.

AlmeIDA, A. W. B. de. Carajás: a guerra dos mapas. Belém: Falângola, 1994. 329p.

ATLAS do Maranhão. Gerência de planejamento e desenvolvimento econômico, Laboratório de Geoprocessamento, UEMA. São Luís: Geplan, 2000. 35p.

ATLAS do Maranhão. Escalas variam. Rio de Janeiro: IBGE, 1984. 104p.

ATLAS do Amapá. Território Federal do Amapá. Rio de Janeiro: Instituto Federal de Desenvolvimento do Amapá (IFDA), Conselho Nacional de Geografia (IBGE), 1966. 40p.

BECKER, B. K. Geopolítica da Amazônia. Rio de Janeiro: Jorge Zahar, 1982.

BECKER, B. K.; EGLER, C. Brazil: new regional power in the world economy. Cambridge: Cambridge University Press, 1992.

BRASIL. Ministério do Planejamento e Orçamento. Indicações para uma nova estratégia de desenvolvimento regional. Brasília: Universa, 1997.

. Ministério do Planejamento e Orçamento. Indicações para uma nova estratégia de desenvolvimento regional. Brasília, 1971, 1974 e 1995.

. Plano Nacional de Viação. Rio de Janeiro: CNT, 1973. 51p.

BUNKER, S. Flimsy joint ventures in fragiles environments. In: BARHAM, B.; BUNKER, S.; O'HEARN, D. (Ed.). States, firms and raw materials. Madison: The University of Wisconsin Press, 1994. p. 261-296.

- Notas sobre a renda do solo e a tributação no Pará. Belém: UFPA, 2001 (Paper do NAEA, 159). 
CARVALHO, D. A queda da renúncia fiscal e acrise recente do padrão de financiamento da Amazônia. Paper do NAEA, Belém, n. 66, 1997.

. Joint ventures em ambientes frágeis: o caso do alumínio na Amazônia. Novos Cadernos do NAEA, Belém, v. 3, n. 1, p. 5-46, 2000.

ELETRONORTE. Relatório diagnóstico: reservatório da usina hidrelétrica de Tucuruí. Brasília: Eletronorte, 1984, v. 1 (Revisão 1).

FERREIRA FILHO, C. Porque perdemos a Batalha da Borracha. Manaus: Edições do Estado do Amazonas, 1965. 373p. (Série Euclides da Cunha).

HURTIENNE, T. Agricultura familiar e desenvolvimento rural sustentável. In: COELHO et al. (org.). Estado e políticas públicas na Amazônia: gestão do desenvolvimento regional. Belém, CEJUP, 2001. p. 177-283.

MACHADO, L. O. Urbanização e mercado de trabalho na Amazônia brasileira. Cadernos do IPPUR, Rio de Janeiro, ano 13, n. 1, p. 109-138, 1999.

MAHAR, D. J. Desenvolvimento econômico da Amazônia: uma análise das políticas governamentais. Rio de Janeiro: IPEA, IMPES, 1978 (Relatório de Pesquisa, 39).

MARTINELO, P. A. "Batalha da Borracha" na Segunda Guerra Mundial e suas conseqüências para o vale amazônico. 1985. 368p. Tese (Doutorado em História Econômica) - Universidade de São Paulo, São Paulo, 1985.

MENDES, A. Estrada para o desenvolvimento. Belém: IDESP, 1971. 243p.

PNUD/IPEA. Atlas de desenvolvimento humano no Brasil. Rio de Janeiro: PNUD, IPEA, FJP, 1997.

OLIVEIRA, F. de. Elegia para uma re(li)gião: SUDENE, Nordeste. Planejamento e conflito de classes. Rio de Janeiro: Paz e Terra, 1972.

A reconquista da Amazônia. In: D'INCAO, M. A.; SILVEIRA, I. M. (org.) A Amazônia e a crise de modernização. Belém: Museu Paraense Emílio Goeldi, 1994. p. 185-196.

RABELO, B. (coord.). Zoneamento ecológico-econômico do sul do estado do Amapá. Macapá: IEPA, 2000. 44p. 
SAWYER, D. Fecundidade e mortalidade na Amazônia: notas sobre as estimativas e interpretações. In: ENCONTRO NACIONAL DE ESTUDOS POPUlACIONAIS, 2, 1980, Águas de São Pedro. Anais... São Paulo: ABEP, 1981. p. 113-183.

. Evolução demográfica, qualidade de vida e desmatamento na Amazônia. In: BRASIL. Ministério do Meio Ambiente. Causas e dinâmica do desenvolvimento na Amazônia. Brasília: MMA, 2001. p. 73-90.

SILVA, M. A. R. da. Royalties da mineração: problemas e perspectivas para promover o desenvolvimento sustentável de regiões mineradoras na Amazônia oriental. In: ENCONTRO NACIONAL DE ECONOMIA, 1997, Recife. Anais... Recife: ANPEC, 1997, v. 2.

SPVEA. Política de desenvolvimento da Amazônia (1954-1960). Rio de Janeiro, 1960. 210p.

SUDAM. II Plano Nacional de Desenvolvimento: Programa de ação do Governo para a Amazônia. Belém, 1976. 100p.

Plano de desenvolvimento da Amazônia (1972-1974). Belém:

Sudam, 1971.

VALVERDE, O.; DIAS, V. A rodovia Belém-Brasília. Rio de Janeiro: Fundação IBGE, 1967. 350p. 